\title{
Reproductive outcomes in rat female offspring from male rats co-exposed to rosuvastatin and ascorbic acid during pre-puberty
}

Gabriel Adan Araujo Leite, Thamiris Moreira Figueiredo, Tainá Louise Pacheco, Marina Trevizan Guerra, Janete Aparecida Anselmo-Franci \& Wilma De Grava Kempinas

To cite this article: Gabriel Adan Araujo Leite, Thamiris Moreira Figueiredo, Tainá Louise Pacheco, Marina Trevizan Guerra, Janete Aparecida Anselmo-Franci \& Wilma De Grava Kempinas (2018) Reproductive outcomes in rat female offspring from male rats co-exposed to rosuvastatin and ascorbic acid during pre-puberty, Journal of Toxicology and Environmental Health, Part A, 81:17, 873-892, DOI: 10.1080/15287394.2018.1504702

To link to this article: https://doi.org/10.1080/15287394.2018.1504702

View supplementary material $₫$

Published online: 06 Aug 2018.

Submit your article to this journal $₫$

山 Article views: 56

View Crossmark data $\nearrow$ 


\title{
Reproductive outcomes in rat female offspring from male rats co-exposed to rosuvastatin and ascorbic acid during pre-puberty
}

\author{
Gabriel Adan Araujo Leite (1) ${ }^{\mathrm{a}, \mathrm{b}}$, Thamiris Moreira Figueiredo ${ }^{\mathrm{b}}$, Tainá Louise Pacheco ${ }^{\mathrm{b}}$, Marina Trevizan Guerra ${ }^{\mathrm{b}}$, \\ Janete Aparecida Anselmo-Francic, and Wilma De Grava Kempinas ${ }^{b}$ \\ ${ }^{a}$ Graduate Program in Cell and Structural Biology, Institute of Biology, State University of Campinas - UNICAMP, Campinas, Brazil;

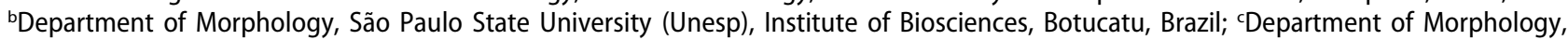 \\ Physiology and Basic Pathology, School of Dentistry of Ribeirão Preto, USP - University of São Paulo, Ribeirão Preto, São Paulo, Brazil
}

\begin{abstract}
Dyslipidemias are occurring earlier in different countries due to the increase of obesity, bad eating habits, and sedentary lifestyle. Rosuvastatin reduces serum cholesterol; however, several studies associated statin exposure with male reproduction impairment. Ascorbic acid (AA) is an antioxidant substance that plays a protective role in the male reproductive system. Male rats were randomly divided into 6 experimental groups $(n=10)$, which received saline solution $0.9 \%, 3$ or $10 \mathrm{mg} / \mathrm{kg} /$ day of rosuvastatin, $150 \mathrm{mg} /$ day of $A A$ or 3 or $10 \mathrm{mg} / \mathrm{kg} /$ day of rosuvastatin associated with $150 \mathrm{mg} /$ day of AA from post-natal day (PND) 23 until PND 53. On PND 100, males were mated with non-treated female rats to obtain the female pups. The day of vaginal opening and the first estrus were assessed in the offspring. Two sets of females were euthanized on the first estrus after PND 42 and PND 75 to evaluate the histology of reproductive organs and hormone levels. A third set was used for sexual behavior and fertility test around PND 75. Female offspring from males exposed or co-exposed to the higher dose of statin exhibited a lower number of corpora lutea during puberty. On sexual maturity, the experimental group from males that were exposed to $3 \mathrm{mg}$ displayed lower uterine luminal epithelium area. Paternal exposure to rosuvastatin at pre-puberty diminished uterine luminal epithelium in female offspring suggesting epigenetic changes were initiated by statin. Ascorbic acid co-administered to pre-pubertal males was able to ameliorate the reproductive damage in rat female offspring in adulthood.
\end{abstract}

ARTICLE HISTORY

Received 21 April 2018

Accepted 23 July 2018

\section{KEYWORDS}

Vitamin C; rosuvastatin; female offspring; reproduction; toxicology

\section{Introduction}

The incidence of dyslipidemias have increased in the pediatric population as a consequence of augmented prevalence of obesity (Jiménez and Ferre 2011) and this disorder was defined as dysfunction of lipid profile that includes increased levels of LDL-cholesterol and VLDL-cholesterol, augmented triglycerides content or reduced HDL-cholesterol concentrations in blood (Jiménez and Ferre 2011; Kwiterovich 2008a, 2008b).

Previous studies reported that pediatric dyslipidemias may be linked to genetic factors such as familial hypercholesterolemia (Cook and Kavey 2011; Ross 2016) or associated with environmental factors such as inappropriate lifestyle, lack of physical exercises and bad eating habits (Izar, Fonseca, and Fonseca 2011; Ross 2016). American Academy of Pediatrics and The National Heart, Lung and Blood Institute recommended lipid-lowering drugs to treat dyslipidemias in children aged 8 to 10 years when diet and physical exercises were not sufficient to lower LDL-cholesterol (Joyce et al. 2016). However, Araujo and Pacce (2016) proposed to treat dyslipidemias in children with statins from 8 to 12 years.

Among the lipid-lowering drugs, statins are considered effective due to their efficient reduction of total cholesterol in the blood (Endres 2006; Istvan 2003; Tandon et al. 2005). Statins decrease cholesterol concentrations by inhibiting the enzyme 3-hydroxy-3-methylglutharyl coenzyme A reductase (HMG-CoA reductase) (Istvan and Deisenhofer 2001; Jiménez and Ferre 2011) and preventing the conversion of HMG-CoA to

CONTACT Gabriel Adan Araujo Leite $\otimes$ gabriel_adan_1990@hotmail.com @ Departamento de Morfologia, Instituto de Biociências, UNESP, Rua Prof. Dr. Antonio Celso Wagner Zanin, s/n, Botucatu 18618-689, SP, Brazil

Color versions of one or more of the figures in the article can be found online at www.tandfonline.com/uteh.

(4) Supplemental data for this article can be accessed here.

(C) 2018 Taylor \& Francis 
mevalonate, thus reducing intermediate isoprenoids and cholesterol formation (Adam and Laufs 2008; Istvan 2003). The incidence rate of statin prescription to treat hypercholesterolemia in the pediatric population represents $63 \%$ of all pharmacotherapies (Liberman, Berger, and Lewis 2009); however, there are no apparent available data specifically for rosuvastatin prescription.

Rosuvastatin is the most recent statin available in the market used for lipid-lowering treatment and shows superior inhibitory effects on cholesterol biosynthesis in relation to the other statins (Holdgate, Ward, and McTaggart 2003; McTaggart 2003; Olsson, McTaggart, and Raza 2002). Statins are recommended to be administered as a daily dose during the evening, although rosuvastatin may be used any time of the day due to its long half-life (Martin, Mitchell, and Schneck 2002). In addition, the long half-life of rosuvastatin enables administration on alternate days; however, this regimen is not as effective as daily dosing of rosuvastatin (Dulay et al. 2009).

In contrast, previous studies demonstrated that rosuvastatin was capable of (1) reducing serum testosterone concentrations in men and rats (Hsieh and Huang 2016; Leite et al. 2014) (2) interfering with male reproductive development in rats (Leite et al. 2017a, 2014) and diminishing rat sperm quality on sexual maturity (Leite et al. 2017b).

Several chemical agents, termed endocrine disruptors, may interfere with puberty timing and acquisition of reproductive capability when humans or animals are exposed to them during critical periods, such as puberty (Stoker et al. 2000; Weatherly and Gosse, 2017), and further, these compounds may produce reproductive impairment in adulthood (Ena et al, 2017; Louis et al. 2017; Perobelli et al. 2012, 2013).

Several studies used different substances that may prevent oxidative stress or reduce impairment attributed drug treatment (Corsetti et al. 2011; Mukhopadhyay et al. 2013; Pandir, Kara, and Kara 2014; Sooriyaarachchi, Narendran, and Gailer 2012). Various medications are important to treat diseases; however adverse effects occur during the period of treatment (Pandir, Kara, and Kara 2014; Sooriyaarachchi, Narendran, and Gailer 2012). Ascorbic acid (AA) is a necessary vitamin for many biological functions including a-tocopherol recycling and collagen biosynthesis (Fernandes et al. 2011a, 2011b; Sönmez, Turk, and Yuce 2005), in addition to being essential for sperm integrity, fertility and diminishing testicular oxidative stress (Agarwal et al 2005; Eskenazi et al. 2005; Fernandes et al. 2011a, 2011b; Shrilatha and Muralidhara 2007). Ascorbic acid was able to prevent reproductive damage during puberty and adulthood in male rats exposed to rosuvastatin during pre-puberty (Leite et al. 2017b, 2017a). Further, AA is an important substance for preventing oxidative stress that leads to sperm DNA damage (Agarwal et al 2005), which might be transmitted to the offspring. Various investigators found that paternal exposure to a toxic compound may affect not only the reproductive capability of the exposed animals but also may compromise reproduction of their male or female offspring (Favareto, De Toledo, and Kempinas 2011; Schagdarsurengin and Steger 2016; Silva et al. 2016; Zhao et al. 2015).

Considering the utilization of lipid-lowering medications for children and adolescents to (1) decrease total cholesterol levels, and (2) prevent cardiovascular diseases and reproductive damage observed in rats following statin exposure, the present study aimed to examine the reproductive parameters in female offspring obtained from rosuvastatin-exposed rats and assess the role of paternal supplementation with AA on female offspring reproductive capacity and fertility.

\section{Material and methods}

\section{Animal experimental protocol}

Male and female nonpathogenic free Wistar rats (45 days of age) were obtained from Central Biotherium of São Paulo State University (UNESP), Botucatu/SP and maintained in the Small Mammal Biotherium of the Morphology Department at the UNESP Biosciences Institute, Botucatu during the experiment. Rats were housed in polypropylene cages $(43 \mathrm{~cm} \times 30 \mathrm{~cm} \times 15 \mathrm{~cm})$ with lab grade pine shavings as bedding. Animals were maintained under controlled temperature $\left(23 \pm 1^{\circ} \mathrm{C}\right)$ and lighting conditions (12:12 hr photoperiod). The health status of the animals was monitored throughout the experiment. Standard rodent chow (Purina 
Labina, Agribrands do Brasil Ltda, Paulínia/SP, Brazil) and filtered tap water were provided ad libitum.

During adulthood, two nulliparous female rats (75 days of age) were mated with one male (90 days of age) during the dark phase of the lighting cycle and day of sperm detection in the vaginal smear of female rats in estrus was considered gestational day 0 (GD 0). Pregnant and lactating female rats were maintained in individual cages. After the birth of pups, their number per litter was culled to 8 on postnatal day (PND) 4 to balance male and female pups (4 each per litter). Litters with fewer than 8 pups were not included in the experimental protocol and were posteriorly euthanized.

\section{Experimental design}

Male pups were randomly distributed into 6 experimental groups on PND 23 ( $n=10$ per group, with one pup per litter for each group). The experimental groups received vehicle (saline solution $0.9 \%$ ), 3 or $10 \mathrm{mg} / \mathrm{kg} /$ day of rosuvastatin diluted in saline solution $0.9 \%$, supplementation with $150 \mathrm{mg}$ /day of ascorbic acid (AA), $3 \mathrm{mg} / \mathrm{kg} /$ day of rosuvastatin associated with $150 \mathrm{mg} /$ day AA or $10 \mathrm{mg} / \mathrm{kg} /$ day rosuvastatin in association with $150 \mathrm{mg} /$ day AA. Ascorbic acid and rosuvastatin were purchased from a commercial pharmacy (Farmácia Botica Oficinal, Botucatu/Brazil). The drugs were administered orally by gavage since PND 23 until PND 53, following male pubertal assay of 31 days recommended by the Environmental Protection Agency (EPA) (Stoker et al. 2000).

The available doses of rosuvastatin utilized by humans to reduce total cholesterol and LDL-cholesterol are between 5 and $40 \mathrm{mg} /$ day (Vaughan and Gotto Jr 2004). Previously Reagan-Shaw, Nihal, and Ahmad (2008) proposed a conversion of animal doses to human equivalent doses (HED) based upon body surface area, using the following formula: $\operatorname{HED}(\mathrm{mg} / \mathrm{Kg})=$ animal dose $(\mathrm{mg} / \mathrm{Kg})$ multiplied by animal $\mathrm{K}_{\mathrm{m}}$ /human $\mathrm{K}_{\mathrm{m}}$. Therefore, the formula employed for obtaining the animal equivalent doses $(\mathrm{AED})$ is $\operatorname{AED}(\mathrm{mg} / \mathrm{Kg})=$ human dose $(\mathrm{mg} / \mathrm{Kg})$ multiplied by human $\mathrm{K}_{\mathrm{m}}$ /animal $\mathrm{K}_{\mathrm{m}}$.

In this study exposure was simulated during childhood and adolescence, thus according to Reagan-Shaw, Nihal, and Ahmad (2008), child weight was considered as $20 \mathrm{~kg}$, body surface area equal to $0.8 \mathrm{~m}^{2}$ and child $\mathrm{K}_{\mathrm{m}}$ equal to 25 . For rats, the investigation considers weight as $0.15 \mathrm{~kg}$ and $\mathrm{K}_{\mathrm{m}}$ equal 6 . In previous experiments from our lab it was found that the mean of body weight is $0.1 \mathrm{~kg}$ during the period of treatment (mean from post-natal day 23 to 53), thus the approximate rat $\mathrm{K}_{\mathrm{m}}$ in this condition is $\mathrm{K}_{\mathrm{m}}=4$. Further, the human doses of 10 and $40 \mathrm{mg}$ of rosuvastatin were selected, and consequently, when applied to the formula, the approximate doses of 3 and $10 \mathrm{mg}$ of statin for the rats were obtained. The doses of AA supplementation were based upon previous studies (Fernandes et al. 2011a, 2011b).

Rats were maintained until PND 100 when were mated with nulliparous female rats to obtain their female offspring (generation F1). After the birth of pups, litters were reduced to 8 on postnatal day (PND) 4 to balance male and female pups (4 each per litter).

Female offspring were evaluated in relation to puberty onset, ovarian and uterine histopathology and hormonal concentrations at the first estrus after PND 42 (one female per litter). Another female per litter was maintained until sexual maturity when sexual behavior test and reproductive performance and fertility test were assessed. The remaining rats were evaluated in relation to estrous cyclicity and then, euthanized on the first estrus after PND 75 to obtain final body weight, reproductive (ovaries, oviducts and uterus) and vital organ weights (pituitary, thyroid, liver, adrenals, kidneys, and brain), hormonal concentrations (progesterone, follicle stimulating hormone (FSH) and luteinizing (LH), ovarian and uterine histopathology and histomorphometric assessment in ovaries and uterus (one female per litter). This experimental design is illustrated in Figure 1.

Animals were monitored in relation to the indications of distress, such as ingestion of food and water and presence of bristling hair during the whole experiment. The experimental protocol followed the Ethical Principles in Animal Research of the Brazil College of Animal Experimentation and was approved by the Bioscience Institute/UNESP Ethics Committee for Animal Experimentation (protocol number 589-CEUA). 


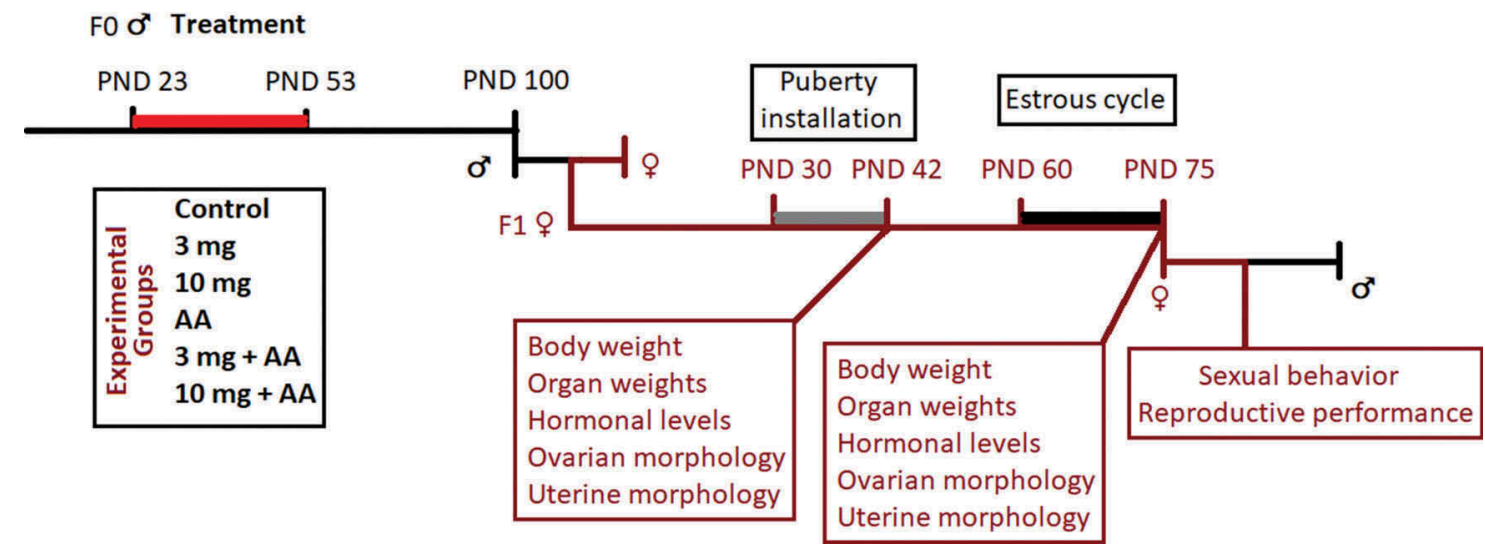

Figure 1. Description of the experimental design.

\section{External physical sign of puberty onset}

Since PND 30, all female pups were assessed daily for complete vaginal opening from 8:00 to 10:00 a.m. After vaginal opening, rats were weighed and evaluated in relation to the day of the first estrus through vaginal fluid cells content from 8:00 to 10:00 a.m., as previously described (Marcondes et al. 2002). Ten $\mu$ l saline $0.9 \%$ solution was inserted into the vagina and subsequently aspirated. Vaginal fluids were placed into slides and posteriorly analyzed under a light microscope (Zeiss, Axiostar Plus, Oberkochen, Germany) at x200 magnification. The estrus phase was characterized by the abundance of cornified vaginal epithelial cells.

\section{Estrous cyclicity}

On PND 60, one female per litter was examined daily until PND 75 in relation to the estrous cyclicity, using cells collected from vaginal fluid (as described above for the first estrus) to determine the estrous cycle phase. The presence and composition of the vaginal cells were utilized to characterize each phase: proestrus, predominance of nucleated epithelial cells; estrus: abundance of cornified epithelial cells; metaestrus, presence of nucleated and cornified epithelial cells and leukocytes; diestrus, predominance of leukocytes, followed by abundant vaginal mucus (Marcondes, Bianchi, and Tanno 2002). Data obtained during the 15 days of analysis were used to estimate the total length of each phase of the cycle in days (proestrus, estrus, metaestrus, and diestrus), the estrous cycle length, and the number of cycles during the assessed period.

\section{Euthanasia of the females, body weight, and organ weights}

Female offspring was weighed on the first estrus immediately after PND 42 or PND 75 (one female per litter in each period) and euthanized following narcosis by $\mathrm{CO}_{2}$ asphyxiation and thereafter, blood was collected from inferior vena cava soon after confirmation of estrus, between 9:00 and 11:30 a.m. Reproductive organs, such as ovaries, oviducts, and uterus with fluid were collected and weighed. Vital organs that play an important role for toxicological parameters, such as kidneys, adrenals, liver, thyroid, pituitary, and brain were extracted and weighed.

\section{Serum hormonal concentrations}

Serum was obtained by centrifugation (2000g, $20 \mathrm{~min}, 4^{\circ} \mathrm{C}$ ) in a refrigerated device and was frozen at $-20^{\circ} \mathrm{C}$ until the moment of hormonal measurements. Progesterone, follicle stimulating hormone (FSH) and luteinizing ( $\mathrm{LH})$ were determined by double-antibody radioimmunoassay. Plasma LH and FSH concentrations were determined using specific kits provided by the National Hormone and Peptide Program (Harbor-UCLA, USA). The primary antibodies for $\mathrm{LH}$ and $\mathrm{FSH}$ were anti-rat LH-S10 and FSH-S11 and the references were LH-RP3 and FSH-RP2, respectively. The lower limit of detection (LOD) for LH was $0.04 \mathrm{ng} / \mathrm{ml}$ and for FSH, $0.2 \mathrm{ng} / \mathrm{ml}$. The intra-assay coefficients of variation were $3.4 \%$ for $\mathrm{LH}$ and $3.0 \%$ for FSH. Serum concentrations of progesterone were determined using specific kits provided 
by MP Biomedicals (Orangeburgh, NY, USA). The intra-assay coefficient of variation was $3.6 \%$ and the lower LOD $0.02 \mathrm{ng} / \mathrm{ml}$. All samples were measured in the same assay to avoid the inter-assay errors.

\section{Histological procedures}

Uterus and left ovary were collected and fixed in Bouin's fluid, embedded in Paraplast ${ }^{\circledR}$ and sectioned in $4 \mu \mathrm{m}$ (transversal sections of the ovary and middle region of the uterus). Sections were stained with hematoxylin and eosin (HE) to assess ovarian and uterine morphology under light microscopy. The evaluation was performed in a blind assay and images obtained using scanned slides and the software Pannoramic Viewer in a personal computer.

Ovarian and uterine cross-sections were randomly selected in three non-serial sections per animal obtained with a distance of $50 \mu \mathrm{m}$ among them. Ovarian follicles were counted and classified based on the different stages of follicular development and morphology, and the number of granulosa cell layers (Borgeest et al. 2002; Talsness et al. 2005).

Ovarian follicles were classified, as follows: primordial and primary follicles (enumerated together), only a cuboidal or squamous granulosa cell layer; preantral follicles, presence of 2-4 granulosa cell layers without an antral space; antral follicles, presence of three or more granulosa cell layer and a defined antral space; and atretic follicles, characterized by the presence of pyknotic granulosa cells, disorganized granulosa cell layer, degenerating oocyte and/or detachment of basement membrane (Borgeest et al. 2002; Talsness et al. 2005). Uterine morphological evaluation aimed to assess the histological appearance of each region of the organ: perimetrium, myometrium, and endometrium (endometrial stroma, uterine glands, and luminal uterine epithelium).

\section{Histomorphometric analyses}

The area of the left ovary was measured using scanned slides and the software Pannoramic Viewer in a personal computer to obtain the number of ovarian follicles and corpora lutea per area of the ovary $\left(\mathrm{mm}^{2}\right)$. In addition, the area of all acidophilic corpora lutea in the left ovary from adult female rats were measured using the software Pannoramic Viewer, and thereafter, the mean area of corpora lutea was obtained per animal. In the uterus, morphometric analyses were performed to measure the area of perimetrium, myometrium, endometrial stroma, luminal uterine epithelium, and total and luminal area of the organ. Further, the number of uterine glands was also quantified.

\section{Evaluation of female sexual behavior}

On the first estrus after PND 75, one female rat per litter was used for the mating tests. The rats were maintained on an inverted $12 \mathrm{hr}$ light-dark cycle, with food and water ad libitum. For evaluation of female sexual behavior, sexually experienced males were allowed 15 mounts on the female. Results were expressed as the lordosis quotient (LQ, number of lordosis/15 mounts $\mathrm{x} 100$ ). All females were used only once during the sexual behavior test.

\section{Fertility and reproductive performance}

This analysis was carried following natural mating. In the case of rats that ejaculated during the evaluation of sexual behavior, couples stayed together for an additional $4 \mathrm{hr}$ enabling a greater number of ejaculations.

Every morning, males were separated from the females, and vaginal smears of each female were examined for the presence of sperm. The day when sperm was found in the vaginal smear was considered day 0 of gestation (GD 0 ). On the 20th day of gestation (GD 20), females were weighed and then, euthanized following narcosis by $\mathrm{CO}_{2}$ asphyxiation and decapitation. After collection of uterus and ovaries, the gravid uterus was weighed and the following parameters were quantified: corpora lutea, implantation sites, reabsorptions, and live fetuses. Fetal and placental weights were also determined.

Based upon these results, the following were determined: gestation rate $=$ number of pregnant females/ number of inseminated females x 100; fertility potential (efficiency of implantation) = implantation sites/ corpora lutea $\mathrm{x} 100$; rate of post-implantation loss $=$ number of implantations - number of live 
fetuses/number of implantations $\mathrm{x}$ 100; sex ratio $=$ number of male fetuses/number of female fetuses x 100 .

\section{Statistical analysis}

The results from different parameters were compared and analyzed among the experimental groups using two-way ANOVA, followed by Bonferroni's test. Differences were considered statistically significant when $\mathrm{p} \leq 0.05$. Statistical analyses were performed on GraphPad Prism (version 5.00).

\section{Results}

The description of main results of female offspring from male rats exposed to the different experimental treatments is shown in Figure 2.

\section{Puberty onset and hormonal concentrations}

The age of vaginal opening and the first estrus on female offspring were similar among the experimental groups (Figure 3). Further, on PND 42 there was an increase in $\mathrm{LH}$ concentrations in female offspring from males exposed to both doses of rosuvastatin in association with AA compared to controls (Figure 4). The augmentation in LH levels was $133.75 \%$ higher in the group $3 \mathrm{mg}$ + AA and rose $95.66 \%$ in the group $10 \mathrm{mg}+\mathrm{AA}$, compared to control (control: $3.23 \pm 0.34 ; 3 \mathrm{mg}$ : $5.11 \pm 0.76$; $10 \mathrm{mg}: 3.54 \pm 0.60$; AA: $3.10 \pm 0.47$; $3 \mathrm{mg}+\mathrm{AA}: 7.55 \pm 0.46 ; 10 \mathrm{mg} \pm \mathrm{AA}: 6.32 \pm 0.67)$ (Figure 4). FSH and progesterone concentrations did not exhibit significant differences among the groups on PND 42 (Figure 4). During sexual maturity, hormonal concentrations of FSH, LH, and progesterone were similar among the experimental groups (Figure 5).

\section{Histopathology, ovarian follicle and corpora lutea quantification and uterine morphometries}

Ovarian histopathological assessment on the first estrus after PND 42 showed a lower number of corpora lutea per area of the organ in female offspring from males exposed to the higher dose of

\begin{tabular}{|c|c|c|}
\hline \multirow[t]{2}{*}{ Parameter } & \multicolumn{2}{|c|}{$\begin{array}{c}\text { Differences between } \\
\text { groups }\end{array}$} \\
\hline & 42PND & 75PND \\
\hline Vaginal opening & $=$ & $=$ \\
\hline First estrus & $=$ & $=$ \\
\hline Estrous cycle & - & $=$ \\
\hline $\mathrm{FSH}$ & $=$ & $=$ \\
\hline LH & $\begin{array}{c}3 \mathrm{mg}+\mathrm{AA} \uparrow \\
10 \mathrm{mg}+\mathrm{AA} \uparrow\end{array}$ & $=$ \\
\hline Progesterone & $=$ & $=$ \\
\hline Primordial/primary follicles & $=$ & $=$ \\
\hline Preantral follicles & $=$ & $=$ \\
\hline Antral follicles & $=$ & $=$ \\
\hline Atretic follicles & $=$ & $=$ \\
\hline Corpora lutea & $\begin{array}{r}10 \mathrm{mg} \downarrow \\
10 \mathrm{mg}+\mathrm{AA} \downarrow \\
\end{array}$ & $=$ \\
\hline Corpora lutea area & - & $10 \mathrm{mg}+\mathrm{AA} \uparrow$ \\
\hline Uterine area & $=$ & $=$ \\
\hline Perimetrium & $=$ & $=$ \\
\hline Miometrium & $=$ & $=$ \\
\hline Endometrial stroma & $=$ & $=$ \\
\hline Luminal epithelium & $=$ & $3 \mathrm{mg} \downarrow$ \\
\hline Luminal area & $=$ & $=$ \\
\hline Number of endometrial glands & $=$ & $=$ \\
\hline Lordosis & - & $=$ \\
\hline Reproductive performance & - & $=$ \\
\hline Body weight & - & $=$ \\
\hline Reproductive organ weights & $=$ & $\begin{array}{c}\text { Ovary } \\
10 \text { mg+AA } \uparrow\end{array}$ \\
\hline Vital organ weights & $=$ & $=$ \\
\hline
\end{tabular}

Figure 2. Description of the main results of female offspring from male rats exposed to the different experimental treatments. No differences between the groups are indicated by the symbol of equal $(=)$ and no evaluation performed in one of the periods is shown as a dash (-) in the table.

rosuvastatin alone (reduction of $49.55 \%$ ) or in association with AA (diminution of $44.33 \%$ ) compared to controls (control: $0.88 \pm 0.06 ; 3 \mathrm{mg}$ : $0.82 \pm 0.08$; $10 \mathrm{mg}: 0.44 \pm 0.05$; AA: $0.73 \pm 0.08$; $3 \mathrm{mg}+\mathrm{AA}: 0.74 \pm 0.06 ; 10 \mathrm{mg} \pm \mathrm{AA}: 0.49 \pm 0.08)$ (Figures 6 and 7). In contrast, follicle quantification per area of the ovary was similar among the groups at the same period (Figure 6).

There was an augmentation of $25.1 \%$ in the area of corpora lutea on sexual maturity, with no marked differences in number of these endocrine structures in the female offspring from males exposed to the association of rosuvastatin and AA compared to controls (control: $0.49 \pm 0.03$; 3 mg: $0.44 \pm 0.03$; 10 mg: $0.43 \pm 0.04$; AA: $0.39 \pm 0.03 ; 3 \mathrm{mg}+\mathrm{AA}: 0.41 \pm 0.02 ; 10 \mathrm{mg}$ \pm AA: $0.61 \pm 0.04$ ) (Figures 7 and 8 ). The number 


\section{Vaginal opening}
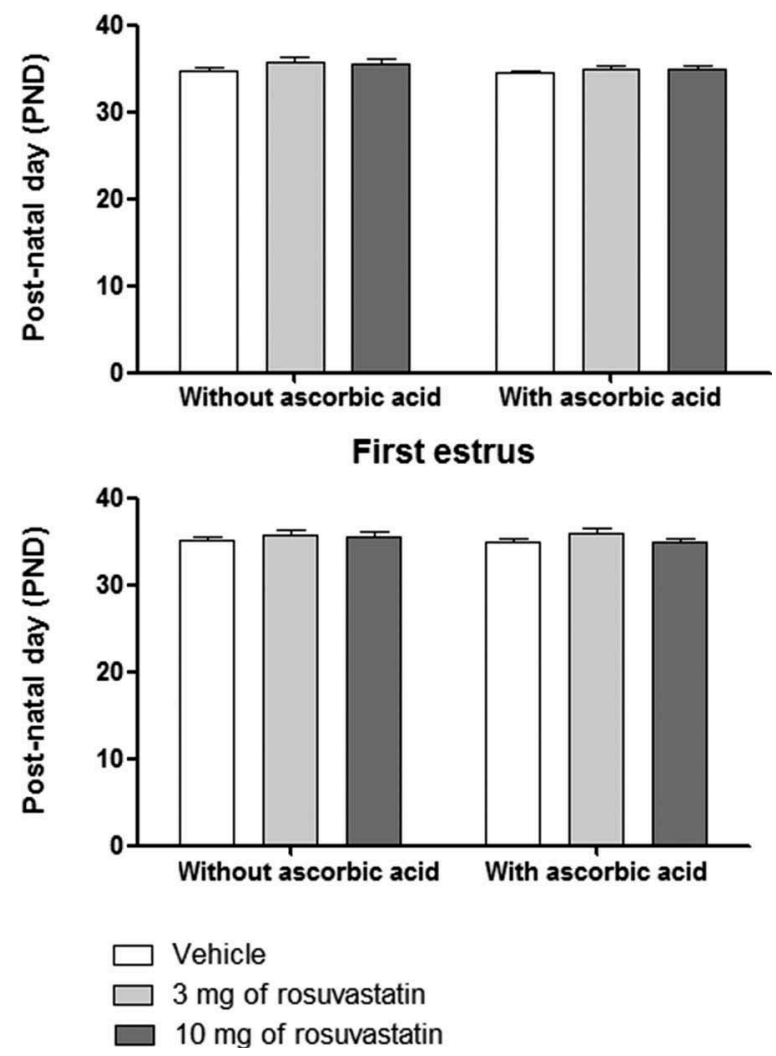

Figure 3. Age of vaginal opening and first estrus in the rat female offspring. Values expressed as mean \pm standard error of mean (SEM). Two-way ANOVA followed by Bonferroni's test. $p<0.05$.

of follicles per area of ovary did not exhibit significant differences among the experimental groups (Figure 8).
Uterine morphometry on PND 42 showed a similar number of endometrial glands and no statistical differences for total and luminal areas of the organ among the experimental groups (Figure 9). Perimetrium, myometrium, endometrial stroma, and luminal uterine epithelial area were similar among the groups (Figure 9). In addition, uterine tissue exhibited similar morphology among the experimental groups (Figure 10).

Uterine luminal epithelial area was $37.17 \%$ lower at sexual maturity in the offspring from males treated with the lower dose of rosuvastatin compared to controls (control: $0.19 \pm 0.02 ; 3 \mathrm{mg}$ : $0.12 \pm 0.01 ; 10 \mathrm{mg}: 0.18 \pm 0.02$; AA: $0.19 \pm 0.01$; $3 \mathrm{mg}+\mathrm{AA}: 0.17 \pm 0.02 ; 10 \mathrm{mg} \pm \mathrm{AA}: 0.19 \pm 0.02$ ) (Figures 10 and 11). Total and luminal areas of the organ and perimetrium, myometrium, and endometrial stroma areas displayed no marked differences among the experimental groups (Figure 11). Further, the number of uterine glands was similar among the groups (Figure 11).

\section{Estrous cycle, sexual behavior testing, and reproductive performance}

Estrous cycle assessment showed similar length and number of cycles during the evaluated period, as well as, comparable duration of each phase of the cycle among the groups (Table 1). In addition, sexual behavior testing and reproductive performance and
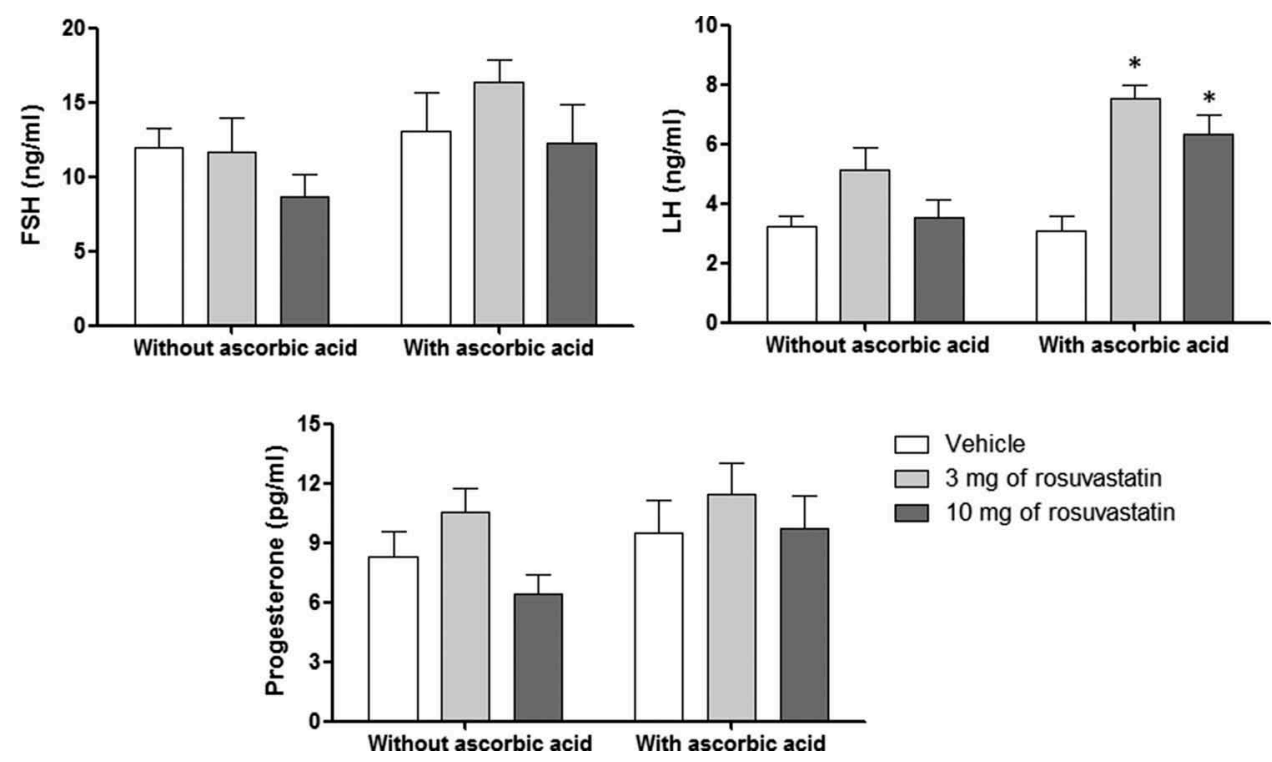

Figure 4. Serum hormonal concentrations $(\mathrm{ng} / \mathrm{ml})$ in rat female offspring at 42 days of age. Values expressed as mean \pm SEM. Twoway ANOVA followed by Bonferroni's test. ${ }^{*} p<0.05$. Different letters indicate statistically significant differences among the groups. 

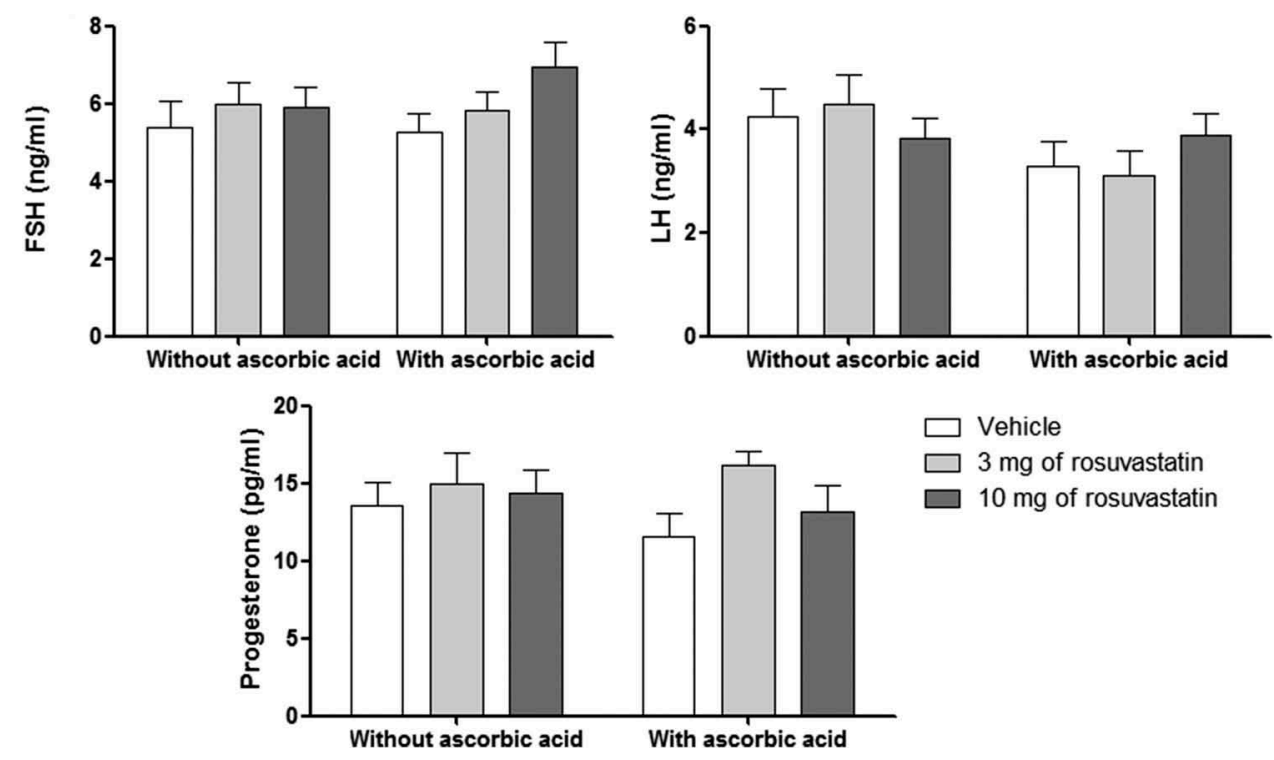

Figure 5. Serum hormonal concentrations $(\mathrm{ng} / \mathrm{ml})$ in rat female offspring at 75 days of age. Values expressed as mean \pm SEM. Twoway ANOVA followed by Bonferroni's test. $p<0.05$.
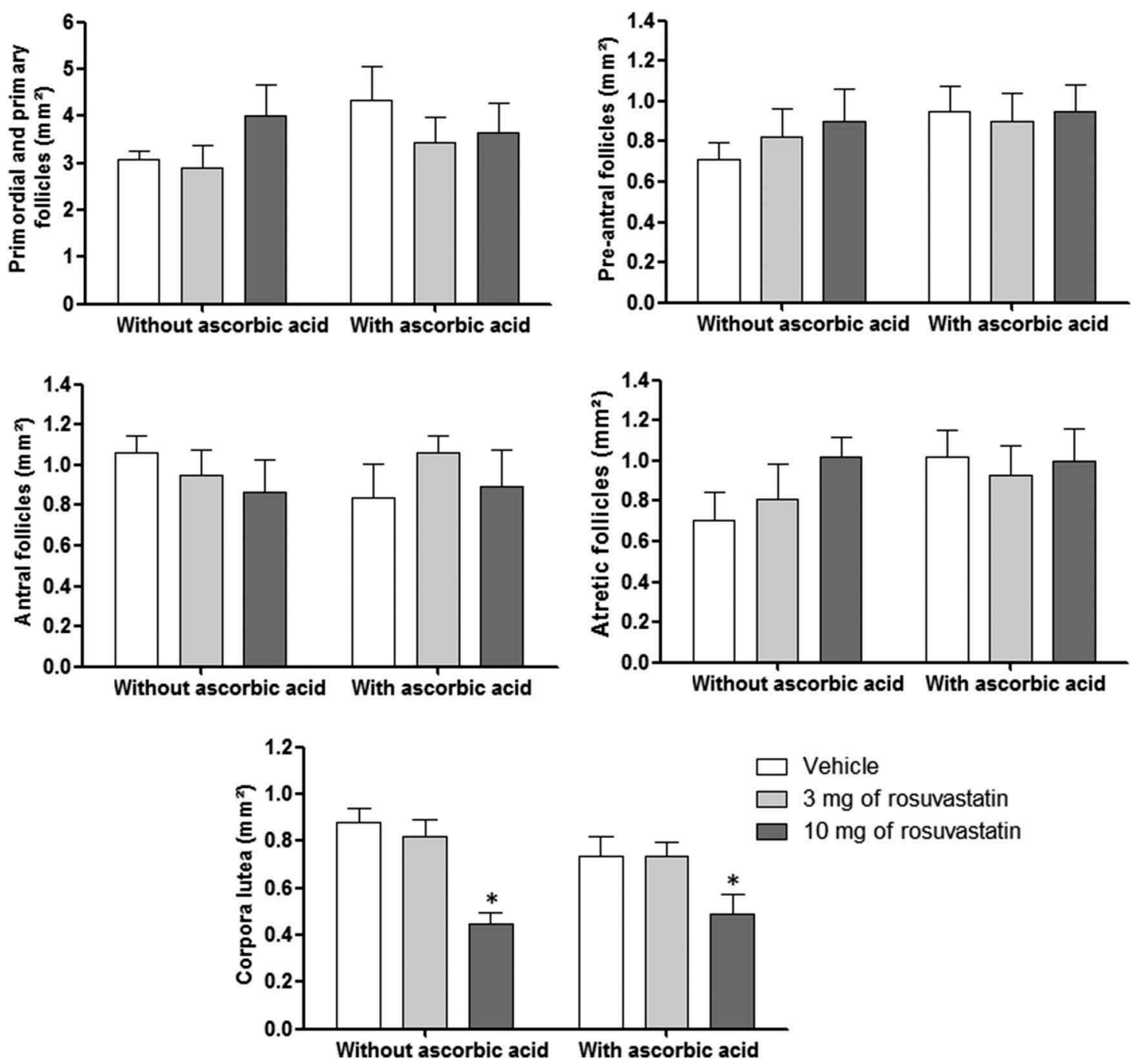

Figure 6. Follicle and corpora lutea quantification in the pubertal ovary of rat female offspring from experimental groups at 42 days of age. Values expressed as mean \pm SEM. Two-way ANOVA followed by Bonferroni's test. ${ }^{*} p<0.05$. Different letters indicate statistically significant differences among the groups. 


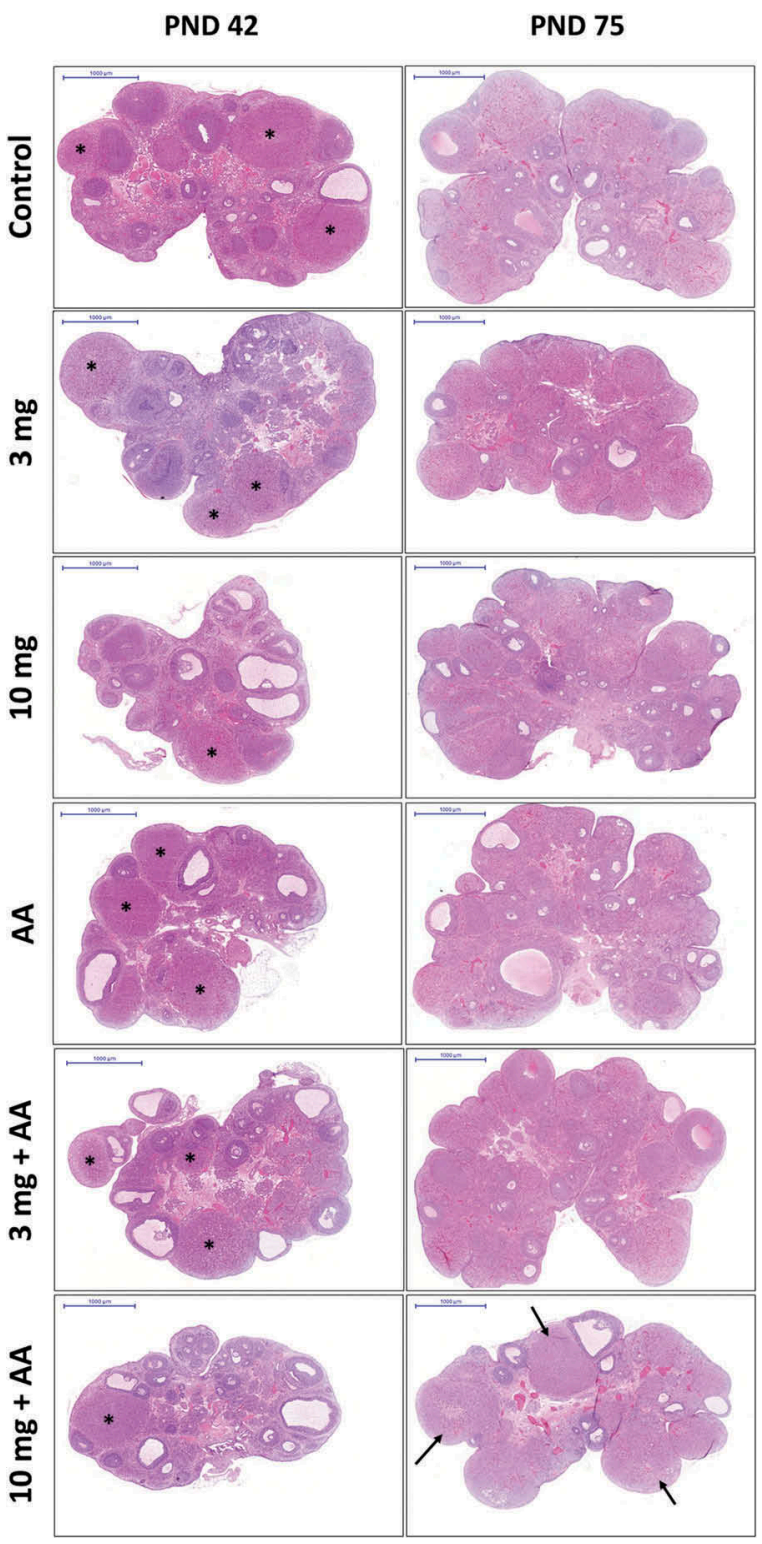

Figure 7. Photomicrography of ovarian sections in the female offspring from experimental groups on postnatal day (PND) 42 and 75. Observe the acidophilic corpora lutea (asterisks) in lower number in the ovaries of female offspring from males exposed and co-exposed to the dose of $10 \mathrm{mg}$ of rosuvastatin. Note the presence of larger corpora lutea (arrows) in the ovary of female offspring from the co-exposed group to the higher dose of statin. Hematoxylin and Eosin (HE). Scale bar $=1000 \mu \mathrm{m}$.

fertility exhibited no marked differences among groups (Figure 12 and Table 2).

\section{Body weight and organ weights}

Final body weight exhibited no marked differences among experimental groups on the first estrus after PND 42 and PND 75 (Tables 3 and 4). Reproductive and vital organ weights did not show significant differences among the groups on the first estrus after PND 42 (Tables 3 and 5). In contrast, ovarian weight was augmented $27.49 \%$ at adulthood in the female offspring from males co-exposed to $10 \mathrm{mg}$ rosuvastatin and $\mathrm{AA}$, in comparison to other groups (Table 4). The remaining reproductive and vital organ weights did not display significant differences among the groups on PND 75 (Tables 4 and 6).

\section{Discussion}

The study is based upon the utilization of lowering-lipid medications by children and adolescents that require this drug to improve their lipid profile by reducing total cholesterol and triglycerides levels or to prevent cardiovascular disease risk. The use of AA proved to be useful to alleviate reproductive impairment in males produced by rosuvastatin exposure during prepuberty (Leite et al. 2017b, 2017a). Although this investigation was performed using non-obese juvenile Wistar rats, this experiment simulates human exposure, since an increased prevalence of atherosclerosis in children and adolescents was noted (Ross 2016; Wiegman et al. 2015) and in addition, more people are deriving benefits from the pleiotropic effects of statins (Ludman et al. 2009; Tandon et al. 2005).

Considering the apparent lack of information regarding the reproductive effects for female offspring from males exposed to lowering-lipid drugs, the present study aimed to assess the reproductive development of female offspring derived from male rats exposed to rosuvastatin during prepuberty. Further, the possible protective role of paternal supplementation with AA for female offspring reproductive development was determined.

Puberty onset is the beginning of cyclical events that direct the anatomy and function of the female reproductive system (Andersson et al. 2013). Increased FSH levels secreted by the pituitary leads to the start of ovarian maturation, which is accompanied by augmented levels of estrogens (Andersson et al. 2013; Guerra et al. 2017). Further, the age of vaginal opening and the first estrus occurrence was considered as an important external sign of puberty installation and is significantly correlated with augmented estrogen levels (U.S. Environmental Protection Agency 1996). In 

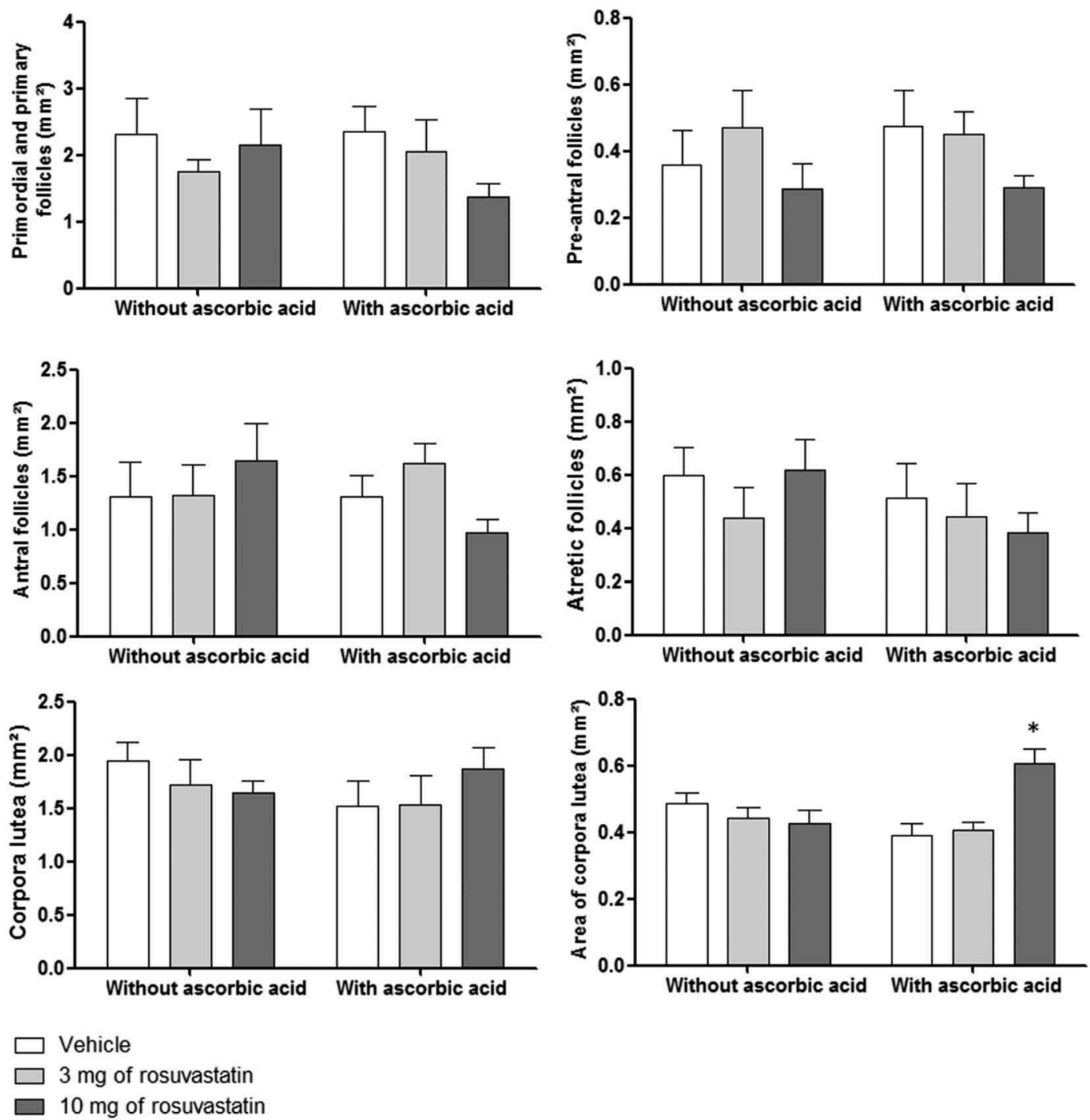

Figure 8. Follicle and corpora lutea quantification and corpora lutea area in the adult ovary of rat female offspring from experimental groups at 75 days of age. Values expressed as mean \pm SEM. Two-way ANOVA followed by Bonferroni's test. ${ }^{*} p<0.05$. Different letters indicate statistically significant differences among the groups.

this study, the age of puberty onset was similar among groups, although the offspring from males exposed to the higher dose of rosuvastatin alone or in association with AA were found to delay ovarian maturation.

Estrogen concentrations increase with follicular growth, which is stimulated by FSH synthetized by anterior pituitary (Andersson et al. 2013; Shaikh 1971). Augmented estrogen levels stimulate LH surge and subsequently, ovulation and luteinization occur and corpora lutea secrete progesterone (Andersson et al. 2013). In this study, during the pubertal period FSH and progesterone levels did not exhibit differences among the groups; however, $\mathrm{LH}$ levels were elevated in offspring from co-exposed groups, indicating that the interaction of these substances was able to interfere genetically (Leite et al. $2017 b$ ) or maybe epigenetically with paternal sperm and consequently increase LH levels in pubertal female offspring. Additional studies are necessary to clarify the molecular mechanisms involved in these findings. At adulthood, $\mathrm{FSH}, \mathrm{LH}$, and progesterone measurements exhibited similar levels among the groups.

Rat ovarian maturation is a result of a cascade of neuroendocrine events that include establishment of pulsatile LH levels and elevated prolactin and $\mathrm{GH}$ concentrations at thirty days of age approximately, thus culminating in puberty installation in female rats (Andrews and Ojeda 1981; Westwood 2008). 

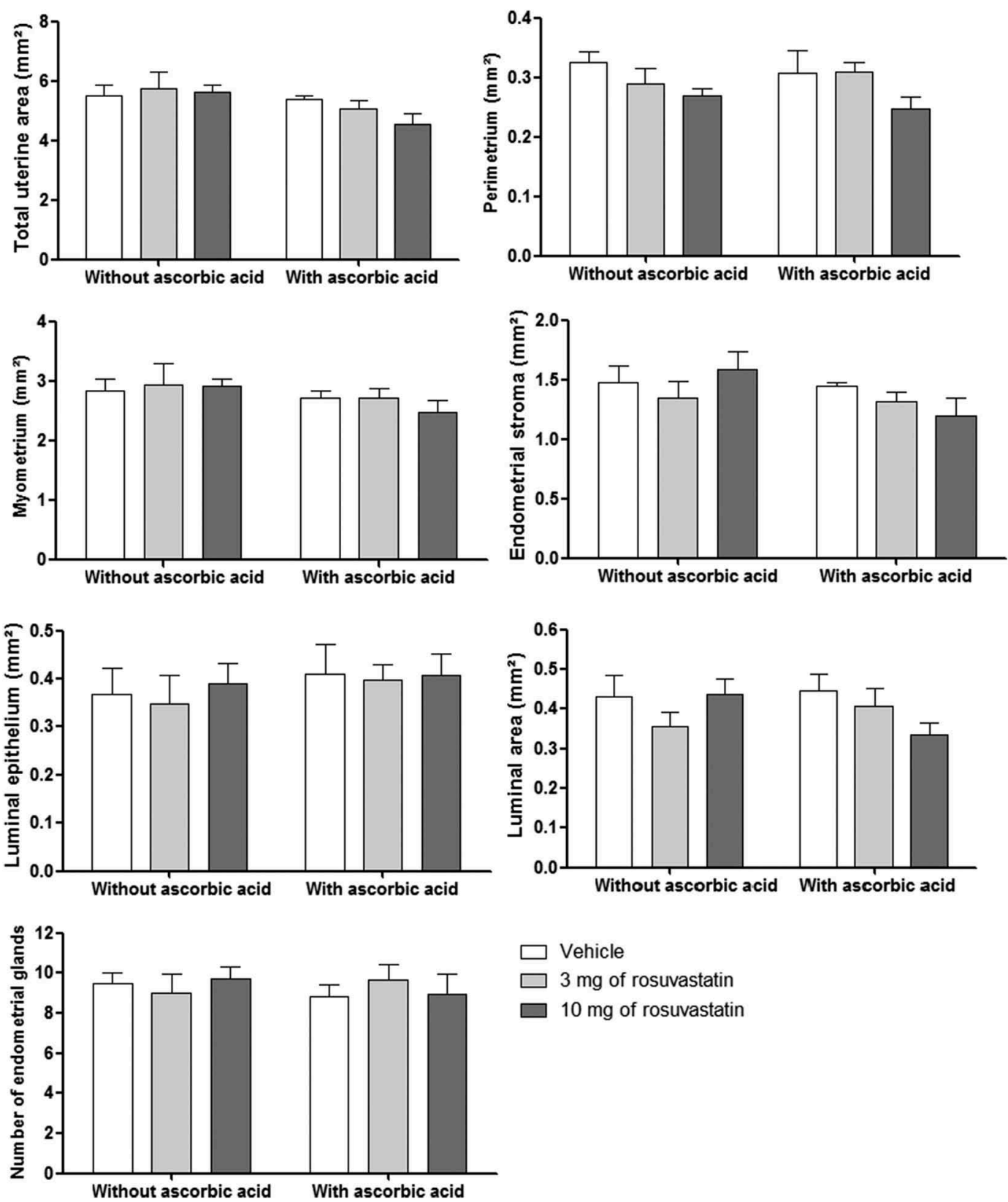

Figure 9. Morphometries in the pubertal uterus of female rat offspring from the experimental groups at 42 days of age. Values expressed as mean \pm SEM. Two-way ANOVA followed by Bonferroni's test. $p<0.05$.

The number of corpora lutea increases with age in prepubertal female rats and is considered as a parameter for interpretation of ovarian development and maturation (Picut et al. 2014a, 2014b). Further, it is known that during puberty the rate of necrotic ova in the medulla decreases (Picut et al. 2014a, 2014b). Pubertal female rats from males exposed to the higher dose of statin alone or in association with AA showed a lower number of corpora lutea, suggesting delayed ovarian maturation in these groups, although these groups did not exhibit delayed puberty installation.
During the pubertal period, elevated LH concentrations in estrus in the offspring from male rats co-exposed to the higher dose of statin may be a consequence of lower ovulatory rate in pubertal females suggesting ovarian hypofunction. Diminished number of ovulated oocytes leads to lower number of corpora lutea and reduced efficiency of negative feedback to inhibit LH release, thus producing higher basal LH levels. This deficiency appears to occur only at the pubertal period, because LH levels and corpora lutea number become similar among the groups at adulthood. 


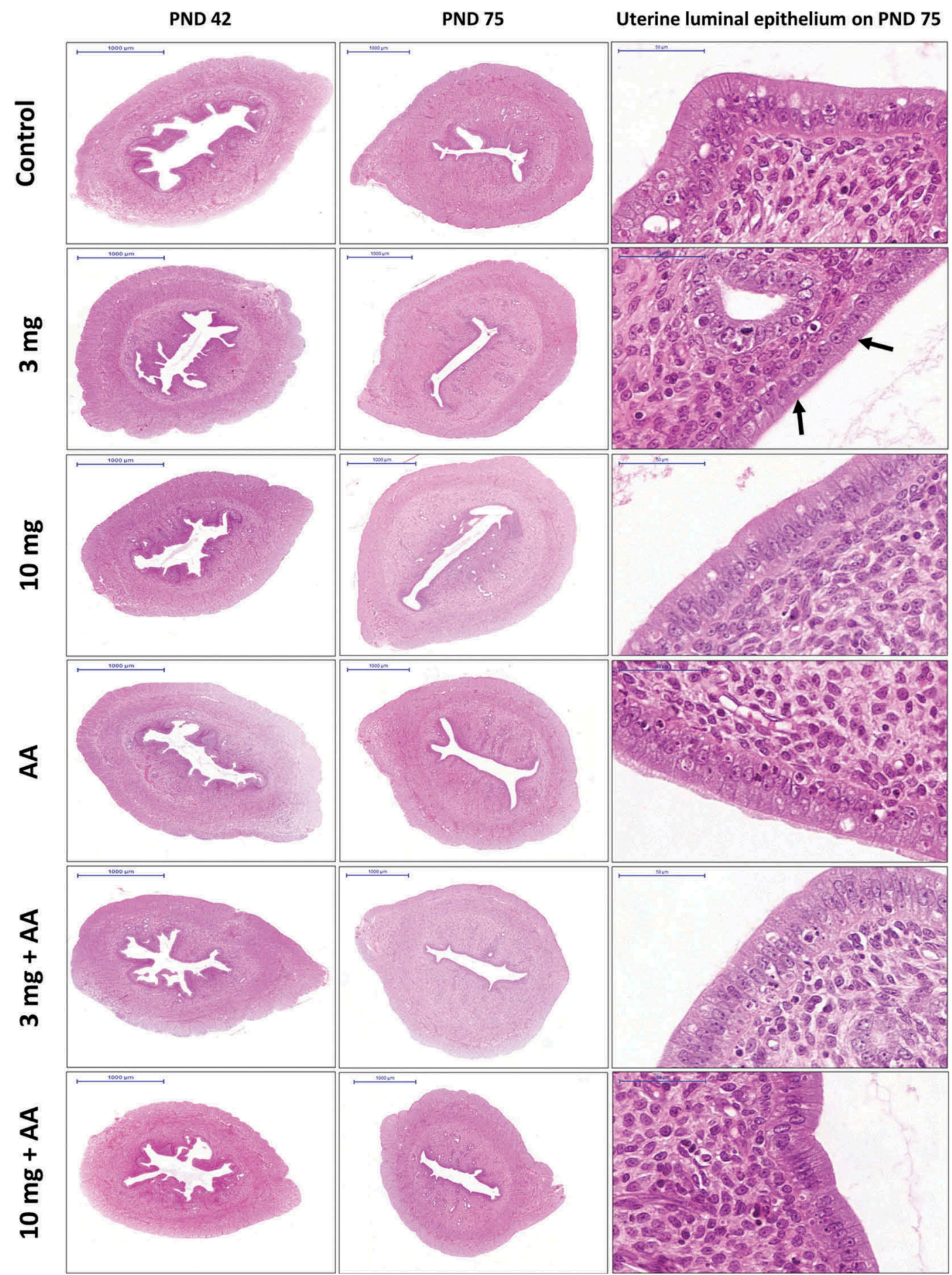

Figure 10. Photomicrography of uterine sections in the female offspring from experimental groups on PND 42 and 75. Observe the lower uterine luminal epithelium height (arrows) in the uterus of female offspring from males exposed to the dose of $3 \mathrm{mg}$ of rosuvastatin. Hematoxylin and Eosin (HE). Scale bar $=1000 \mu \mathrm{m}$ or $50 \mu \mathrm{m}$.

During the pubertal period, uterus demonstrates a higher luminal uterine epithelium, a columnar epithelium, in addition to a common degeneration in luminal epithelial cells and the presence of leukocyte infiltration on endometrial stroma (Picut et al. 2014b). Pubertal uterine tissues showed a similar morphological aspect among the experimental groups in this study. Further, uterine morphometries displayed no marked differences in relation to the area of each region of the organ.

Hormonally mediated effects on the female reproductive system may occur in different ways, such as 

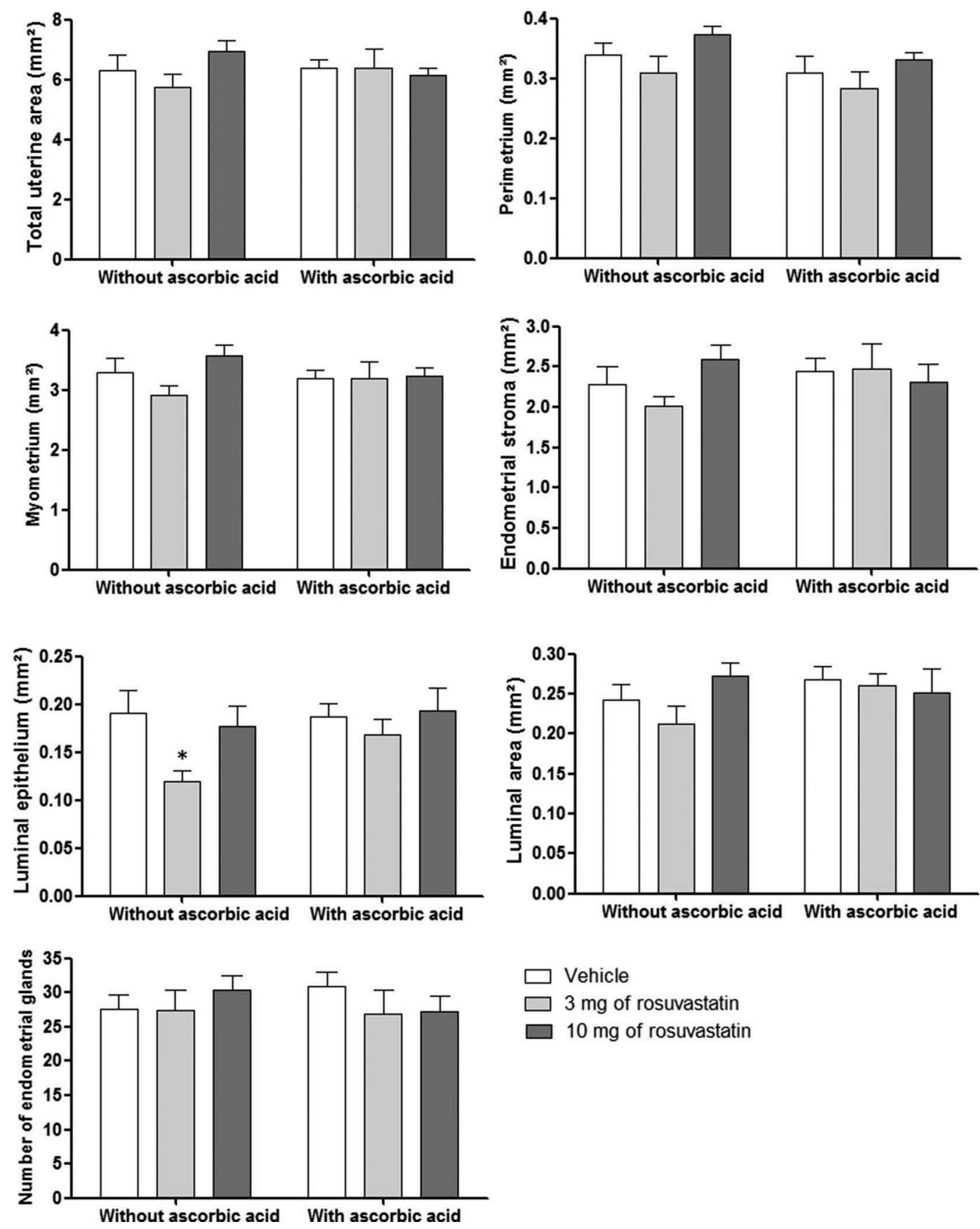

Figure 11. Morphometries in the adult uterus of female rat offspring from the experimental groups at 75 days of age. Values expressed as mean \pm SEM. Two-way ANOVA followed by Bonferroni's test. ${ }^{*} p<0.05$. Different letters indicate statistically significant differences among the groups.

disrupting estrous cycle, organ weights changes and histopathological alterations (Andersson et al. 2013). Uterine epithelium is a tissue highly responsive to estradiol concentrations, since augmented estradiol concentrations leads to increased height of the epithelium and thicker endometrial stroma (Uslu et al. 2013) and lower estradiol concentrations results in epithelial atrophy (Andersson et al. 2013). In this investigation, female offspring from male rats exposed to the lower dose of statin exhibited a lower columnar uterine epithelium and diminished area of the luminal epithelial uterine compartment. Although estradiol concentrations were not measured due to lack of reliable kits for radioimmunoassay, it is conceivable that histopathological finding correlated with a possible reduction in estradiol concentrations in this group.

Previous in vitro studies reported that thecainterstitial cells exposed to simvastatin, another 
statin, exhibited decreased isoprenylation and expression of CYP17A1, thus leading to diminished androgen production (Ortega et al. 2012, 2014). In view of lower concentration of androgens that are synthesized by theca-interstitial cells due to statin exposure, granulosa cells may be producing low estrogen levels because they are receiving lower amounts of substrates to be aromatized to estradiol.

In the adult rat ovary all stages of follicles at all phases of estrous cycles as well as corpora lutea are present; however, corpus luteum shows different morphologies depending upon the phase of the estrous cycle (Westwood 2008). During the estrus phase, the number of follicles and corpora lutea per area of the ovary was similar among the groups. On the other hand, female offspring from the group coexposed to $10 \mathrm{mg}$ of rosuvastatin showed increased area of corpora lutea without elevation in serum progesterone concentrations and in number of these endocrine structures. Indeed, progesterone secretion by corpora lutea in estrus is basal and corpora lutea only show their ability to secrete progesterone in metaestrus, when progesterone surge occurs. In addition, elevated corpora lutea area may be associated with increased prolactin levels in females.

Final body weight evaluation provides substantial information regarding the health status of the animals (Clegg, Perreault, and Klinefelter 2001). Further, reproductive organ weights provide information regarding the reproductive system (Clegg, Perreault, and Klinefelter 2001) and vital organ weights may indicate a general systemic health condition of the animals. Data demonstrated that there was a rise in ovarian weight in female offspring from males co-exposed to $10 \mathrm{mg}$ of statin and AA. This result is reinforced by larger corpora lutea area exhibited in this experimental group. Body weight and remaining organ weights were similar among the groups.

Interference with the reproductive function of female rat is often expressed as a disturbance in length of estrous cycle or histopathological changes in reproductive organs (Westwood 2008); thus, estrous cycle monitoring provides information regarding female reproductive status. Data showed no marked changes in estrous cycle dynamics in female offspring from male rats exposed to rosuvastatin and/or AA. 


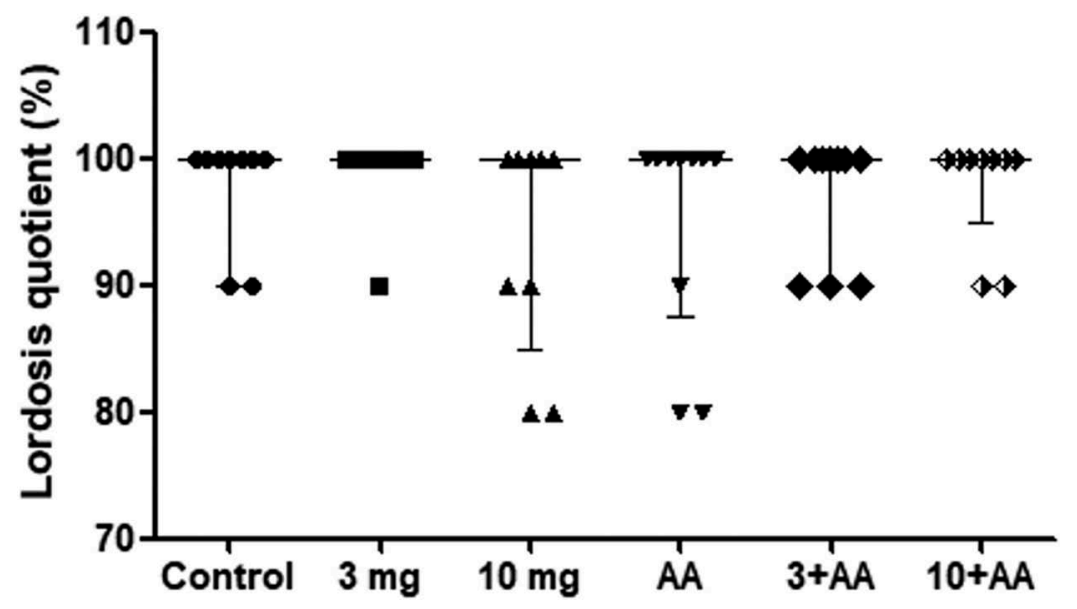

Figure 12. Lordosis quotient in the female rat offspring from the experimental groups on PND 75. Values expressed as median and interquartile intervals. Two-way ANOVA followed by Bonferroni's test. $p<0.05$.

The lordotic posture is the main sign of female rat receptivity (Pfaff and Sakuma 1979; Veening, Coolen, and Gerrits 2013), which is only performed under adequate hormonal conditions (Pfaff and Sakuma 1979; Veening, Coolen, and Gerrits 2013). Further, lordosis is a graded response and may be performed in different intensities depending upon female hormonal status, environmental conditions or male rat sexual behavior (Pattij et al. 2005; Veening, Coolen, and Gerrits 2013). Lordosis quotient did not exhibit significant differences among the experimental groups in this study, thus indicating that paternal exposure to rosuvastatin or even AA did not appear to alter sexual behavior in female offspring.

Epidemiological data regarding post-implantation loss rates in non-treated lab rodents is approximately $10 \%$ or lower (Jauniaux, Poston, and Burton 2006). In this study, reproductive performance did not exhibit marked differences among the groups and post-implantation loss rate was approximately $10 \%$ or less thus suggesting that paternal treatments with statin and AA did not appear to affect these parameters.

Previous studies suggested epigenetic changes were attributed to statin exposure (Bustan and Jawad 2017; Leite et al. 2018). Bustan and Jawad (2017) associated paternal or maternal exposure to atorvastatin or rosuvastatin with alterations in fertility in their offspring. In addition, Leite et al. 2018 indicated that prepubertal male rats exposed to rosuvastatin showed impairment to the reproductive system in the male offspring.

Ascorbate, an intracellular form of ascorbic acid, regulates DNA demethylation and histone demethylation (Young, Zuchner, and Wang 2015), thus presenting an important epigenetic role. Leite et al. (2018) found that paternal supplementation with AA ameliorated the reproductive damage in the male offspring attributed to rosuvastatin, probably due to AA action on inhibition of genetic and epigenetic changes in paternal spermatozoa.

This constitutes a novel report regarding the reproductive effects for female offspring from male rats exposed to statins and/or supplemented with AA. There are few studies concerning statin exposure and reproductive effects or even reporting intergenerational reproductive effects affecting female offspring. Data suggest epigenetic effects in addition to increased paternal sperm DNA fragmentation associated with rosuvastatin exposure as previously reported (Leite et al. 2017b). Further studies are necessary to elucidate the molecular mechanisms involved in the promotion of female reproductive damage mediated by paternal sperm changes.

\section{Conclusions}

In summary, female offspring from males exposed to the lower dose of statin showed lower columnar 
Table 2. Reproductive performance and fertility test in the female offspring from experimental groups after sexual behavior testing on PND 75.

\begin{tabular}{|c|c|c|c|c|c|c|}
\hline & \multicolumn{6}{|c|}{ Experimental Groups ( $\mathrm{n}=9$ or 10 ) } \\
\hline & Control & $3 \mathrm{mg}$ & $10 \mathrm{mg}$ & AA & $3 \mathrm{mg}+\mathrm{AA}$ & $10 \mathrm{mg}+\mathrm{AA}$ \\
\hline Gestational rate (\%) & $75 \%$ & $100 \%$ & $88.88 \%$ & $100 \%$ & $90 \%$ & $80 \%$ \\
\hline${ }^{1}$ Fertility test $(\%)$ & $100(90.80-100)$ & $96.67(27.23-100)$ & $93.54(88.08-98.61)$ & $93.30(87.98-100)$ & $100(75.15-100)$ & $93.33(88.24-100)$ \\
\hline $\begin{array}{l}{ }^{1} \text { Post-implantation } \\
\text { loss (\%) }\end{array}$ & $3.12(0-8.60)$ & $0.0(0-7.14)$ & $5.88(0-8.01)$ & $7.69(0-13.33)$ & $11.76(0-14.84)$ & $0(0-10.00)$ \\
\hline${ }^{1}$ Sex ratio (M:F) & $1.00(0.67-1.87)$ & $1.40(0.40-2.83)$ & $1.54(1.19-2.00)$ & $1.43(0.66-2.00)$ & $1.17(0.40-1.50)$ & $1.33(1.00-1.75)$ \\
\hline $\begin{array}{l}\text { 2Body weight } \\
\text { (GD20) }\end{array}$ & $374.70 \pm 13.39$ & $353.70 \pm 14.70$ & $359.30 \pm 12.28$ & $348.10 \pm 9.87$ & $340.00 \pm 16.91$ & $340.30 \pm 20.01$ \\
\hline${ }^{2}$ Gravid uterus & $64.40 \pm 3.58$ & $57.15 \pm 8.67$ & $62.64 \pm 4.82$ & $61.94 \pm 1.24$ & $50.13 \pm 9.51$ & $56.41 \pm 7.46$ \\
\hline${ }^{2}$ Male fetus weight & $2.87 \pm 0.10$ & $2.83 \pm 0.16$ & $2.96 \pm 0.06$ & $3.05 \pm 0.08$ & $3.21 \pm 0.07$ & $2.97 \pm 0.17$ \\
\hline $\begin{array}{l}{ }^{2} \text { Female fetus } \\
\text { weight }\end{array}$ & $2.56 \pm 0.14$ & $2.69 \pm 0.13$ & $2.85 \pm 0.11$ & $2.89 \pm 0.06$ & $3.01 \pm 0.05$ & $2.87 \pm 0.15$ \\
\hline $\begin{array}{l}\text { 2Placenta weight } \\
\text { from male fetus }\end{array}$ & $0.57 \pm 0.02$ & $0.53 \pm 0.02$ & $0.55 \pm 0.01$ & $0.53 \pm 0.01$ & $0.53 \pm 0.02$ & $0.51 \pm 0.02$ \\
\hline $\begin{array}{l}\text { 2Placenta weight } \\
\text { from female fetus }\end{array}$ & $0.54 \pm 0.01$ & $0.49 \pm 0.02$ & $0.52 \pm 0.03$ & $0.52 \pm 0.02$ & $0.55 \pm 0.04$ & $0.49 \pm 0.02$ \\
\hline
\end{tabular}

Values expressed as median and interquartile intervals ${ }^{1}$ or mean $\pm \mathrm{SEM}^{2}, p>0.05$. Two-way ANOVA followed by Bonferroni's test.

Table 3. Body weight and reproductive organ weights in the female offspring from experimental groups on first estrus after PND 42.

\begin{tabular}{lcccccc}
\hline & \multicolumn{5}{c}{ Experimental Groups $(\mathrm{n}=10)$} \\
\cline { 2 - 6 } & Control & $3 \mathrm{mg}$ & $10 \mathrm{mg}$ & $\mathrm{AA}$ & $3 \mathrm{mg}+\mathrm{AA}$ & $10 \mathrm{mg}+\mathrm{AA}$ \\
\hline Body weight (g) & $142.50 \pm 4.71$ & $142.20 \pm 4.57$ & $139.70 \pm 4.36$ & $143.40 \pm 3.42$ & $141.60 \pm 3.14$ & $143.00 \pm 3.72$ \\
Ovaries (mg/100g BW) & $43.26 \pm 3.13$ & $46.21 \pm 5.36$ & $40.10 \pm 2.02$ & $39.32 \pm 2.96$ & $43.24 \pm 3.07$ & $40.67 \pm 2.24$ \\
Oviducts (mg/100g BW) & $18.49 \pm 1.16$ & $17.76 \pm 1.20$ & $16.83 \pm 0.83$ & $17.36 \pm 1.15$ & $17.35 \pm 1.00$ & $16.21 \pm 1.03$ \\
Uterus (mg/100g BW) & $212.20 \pm 18.76$ & $200.80 \pm 19.49$ & $226.10 \pm 15.91$ & $212.30 \pm 31.31$ & $199.50 \pm 7.43$ & $191.60 \pm 13.70$ \\
\hline
\end{tabular}

Values expressed as mean \pm SEM, $p>0.05$. Two-way ANOVA followed by Bonferroni's test. BW = body weight.

Table 4. Body weight and reproductive organ weights in the female offspring from experimental groups on first estrus after PND 75.

\begin{tabular}{|c|c|c|c|c|c|c|}
\hline & \multicolumn{6}{|c|}{ Experimental Groups $(n=10)$} \\
\hline & Control & $3 \mathrm{mg}$ & $10 \mathrm{mg}$ & $\mathrm{AA}$ & $3 \mathrm{mg}+\mathrm{AA}$ & $10 \mathrm{mg}+\mathrm{AA}$ \\
\hline Body weight (g) & $247.30 \pm 7.94^{a}$ & $248.40 \pm 7.87^{a}$ & $245.80 \pm 3.65^{a}$ & $231.60 \pm 4.89^{a}$ & $241.30 \pm 4.29^{a}$ & $239.00 \pm 6.85^{a}$ \\
\hline Ovaries (mg/100g BW) & $35.54 \pm 1.49^{a}$ & $35.06 \pm 1.84^{\mathrm{a}}$ & $36.23 \pm 2.34$ & $36.94 \pm 2.16^{a}$ & $37.08 \pm 2.61^{a}$ & $45.31 \pm 2.61^{b}$ \\
\hline Oviducts (mg/100g BW) & $11.67 \pm 0.32^{\mathrm{a}}$ & $11.60 \pm 0.76^{\mathrm{a}}$ & $11.06 \pm 0.50^{\mathrm{a}}$ & $12.43 \pm 0.46^{\mathrm{a}}$ & $12.61 \pm 0.89^{a}$ & $13.97 \pm 0.99^{\mathrm{a}}$ \\
\hline Uterus (mg/100g BW) & $143.80 \pm 6.05^{\mathrm{a}}$ & $139.10 \pm 8.75^{\mathrm{a}}$ & $151.00 \pm 6.23^{\mathrm{a}}$ & $150.50 \pm 6.48^{a}$ & $153.10 \pm 8.62^{a}$ & $167.00 \pm 13.05^{\mathrm{a}}$ \\
\hline
\end{tabular}

Values expressed as mean \pm SEM, $p<0.05$. Two-way ANOVA followed by Bonferroni's test. Different letters indicate statistically significant differences among the groups. $\mathrm{BW}=$ body weight.

Table 5. Vital organ weights in the female offspring from experimental groups on first estrus after PND 42.

\begin{tabular}{lcccccc}
\hline & \multicolumn{5}{c}{ Experimental Groups $(\mathrm{n}=10)$} \\
\cline { 2 - 6 } & Control & $3 \mathrm{mg}$ & $10 \mathrm{mg}$ & $\mathrm{AA}$ & $3 \mathrm{mg}+\mathrm{AA}$ & $10 \mathrm{mg}+\mathrm{AA}$ \\
\hline Pituitary $(\mathrm{mg} / 100 \mathrm{~g} \mathrm{BW})$ & $4.39 \pm 0.24$ & $5.07 \pm 0.41$ & $5.06 \pm 0.20$ & $4.93 \pm 0.36$ & $4.73 \pm 0.28$ & $4.29 \pm 0.30$ \\
Thyroid $(\mathrm{mg} / 100 \mathrm{~g} \mathrm{BW})$ & $7.53 \pm 0.50$ & $7.59 \pm 0.34$ & $8.18 \pm 0.51$ & $7.79 \pm 0.68$ & $7.72 \pm 0.60$ & $7.81 \pm 0.48$ \\
Liver $(\mathrm{g} / 100 \mathrm{~g} \mathrm{BW})$ & $7.79 \pm 0.31$ & $7.82 \pm 0.33$ & $7.20 \pm 0.25$ & $7.52 \pm 0.20$ & $7.49 \pm 0.17$ & $7.33 \pm 0.29$ \\
Adrenal (mg/100g BW) & $17.80 \pm 0.52$ & $17.70 \pm 1.16$ & $17.17 \pm 1.00$ & $15.78 \pm 1.29$ & $16.49 \pm 1.23$ & $17.19 \pm 1.28$ \\
Kidney (g/100g BW) & $535.10 \pm 14.87$ & $508.20 \pm 14.06$ & $525.90 \pm 15.05$ & $513.80 \pm 12.08$ & $517.90 \pm 12.50$ & $522.20 \pm 14.49$ \\
Brain (g/100g BW) & $1.15 \pm 0.04$ & $1.17 \pm 0.03$ & $1.19 \pm 0.04$ & $1.19 \pm 0.03$ & $1.21 \pm 0.03$ & $1.17 \pm 0.02$ \\
\hline
\end{tabular}

Values expressed as mean \pm SEM, $p>0.05$. Two-way ANOVA followed by Bonferroni's test. BW = Body weight.

uterine epithelium, indicative of reduced estradiol concentrations. Data suggest important genetic and/or epigenetic alterations in paternal sperm mediated by statin exposure. Ascorbic acid, when administered to males, is capable of protecting paternal sperm thus reducing the reproductive impairment on female offspring from males exposed to statin. 
Table 6. Vital organ weights in the female offspring from experimental groups on first estrus after PND 75.

\begin{tabular}{lcrrrrr}
\hline & \multicolumn{5}{c}{ Experimental Groups $(\mathrm{n}=10)$} \\
\cline { 2 - 6 } & \multicolumn{1}{c}{ Control } & \multicolumn{1}{c}{$3 \mathrm{mg}$} & $10 \mathrm{mg}$ & $\mathrm{AA}$ & $3 \mathrm{mg}+\mathrm{AA}$ & $10 \mathrm{mg}+\mathrm{AA}$ \\
\hline Pituitary $(\mathrm{mg} / 100 \mathrm{~g} \mathrm{BW})$ & $5.11 \pm 0.26$ & $4.99 \pm 0.20$ & $4.68 \pm 0.24$ & $4.60 \pm 0.52$ & $4.89 \pm 0.17$ & $4.60 \pm 0.36$ \\
Thyroid (mg/100g BW) & $7.53 \pm 0.50$ & $6.98 \pm 0.69$ & $5.60 \pm 0.32$ & $6.69 \pm 0.43$ & $5.51 \pm 0.28$ & $6.42 \pm 0.30$ \\
Liver (g/100g BW) & $3.57 \pm 0.06$ & $3.56 \pm 0.08$ & $3.56 \pm 0.09$ & $3.69 \pm 0.05$ & $3.52 \pm 0.05$ & $3.67 \pm 0.09$ \\
Adrenal (mg/100g BW) & $21.04 \pm 1.30$ & $19.23 \pm 1.46$ & $19.35 \pm 0.77$ & $20.85 \pm 1.04$ & $19.64 \pm 0.79$ & $18.97 \pm 1.07$ \\
Kidney (g/100g BW) & $408.00 \pm 14.58$ & $374.60 \pm 9.69$ & $380.10 \pm 10.96$ & $393.00 \pm 13.01$ & $378.40 \pm 8.74$ & $388.00 \pm 11.21$ \\
Brain (g/100g BW) & $0.75 \pm 0.02$ & $0.73 \pm 0.02$ & $0.73 \pm 0.01$ & $0.77 \pm 0.01$ & $0.77 \pm 0.02$ & $0.78 \pm 0.02$ \\
\hline
\end{tabular}

Values expressed as mean \pm SEM, $p>0.05$. Two-way ANOVA followed by Bonferroni's test. BW = Body weight.

\section{Acknowledgments}

The authors are grateful to to José Eduardo Bozano, from the Department of Morphology, Institute of Biosciences, UNESP, Botucatu/SP - Brazil, for his excellent technical assistance and to Dr. Ruither de Oliveira Gomes Carolino, from the Department of Morphology, Stomatology and Physiology, School of Dentistry, University of São Paulo - USP, Ribeirão Preto/SP, Brazil, for his contributions to hormonal measurements.

\section{Funding}

This research was financially supported by São Paulo Research Foundation (FAPESP) (Grants \#013/22495-1 and \#014/13659-3), National Council for Scientific and Technological Development (CNPq) (Grant 308842/2013-8) and Coordination for the Improvement of Higher Education Personnel (CAPES).

\section{Conflicts of interest}

The authors declare that there are no conflicts of interest.

\section{ORCID}

Gabriel Adan Araujo Leite (D) http://orcid.org/0000-00029437-6310

\section{References}

Adam, O., and U. Laufs. 2008. Antioxidative effects of statins. Archives of Toxicology 82:885-92. doi:10.1007/s00204-0080344-4.

Agarwal, A., S. A. Prabhakaran, and T. M. Said. 2005. Prevention of oxidative stress injury to sperm. Journal of Andrology 26:654-60. doi:10.2164/jandrol.05016.

Andersson, H., S. Rehm, D. Stanislaus, and E. W. Charles. 2013. Scientific and regulatory policy committee (SRPC) paper : Assessment of circulating hormones in nonclinical toxicity studies. Toxicogical Pathologists 41:921-34. doi:10.1177/0192623312466959.
Andrews, W. W., and S. R. Ojeda. 1981. Secretory profile in conscious, free-moving female rats during the time of puberty. Endocrinology 109:2032-39. doi:10.1210/endo109-4-1067.

Araujo, M. B., and M. S. Pacce. 2016. A 10-year experience using combined lipid-lowering pharmacotherapy in children and adolescents. Journal of Pediatric Endocrinology \& Metabolism : JPEM 29:1285-91. doi:10.1515/jpem-20160117.

Borgeest, C., D. Symonds, L. P. Mayer, P. B. Hoyer, and J. A. Flaws. 2002. Methoxychlor may cause ovarian follicular atresia and proliferation of the ovarian epithelium in the mouse. Toxicological Sciences : an Official Journal of the Society of Toxicology 68:473-78. doi:10.1093/toxsci/68.2.473.

Bustan, A. A., and A. M. Jawad. 2017. The effect of two types of statins (rosuvastatin and atorvastatin) on the fertility of male and female mice. British Journal Medica Researcher 19:1-11.

Clegg, E. D., S. D. Perreault, and G. R. Klinefelter. 2001. Assessment of male reproductive toxicology. In Principles and Methods of Toxicology, ed. A. W. Hayes, 1263-99. 4th ed. Philadelphia, PA: Taylor \& Francis.

Cook, S., and R. E. W. Kavey. 2011. Dyslipidemia and pediatric obesity. Pediatric Clinics of North America 58:1363-73. doi:10.1016/j.pcl.2011.09.003.

Corsetti, G., A. Stacchiotti, L. Tedesco, G. D’Antona, E. Pasini, F. S. Dioguardi, E. Nisoli, and R. Rezzani. 2011. Essential amino acid supplementation decreases liver damage induced by chronic ethanol consumption in rats. International Journal Immunopathol Pharmacology 24:611-19. doi:10.1177/039463201102400307.

Dulay, D., S. A. LaHaye, K. A. Lahey, and A. G. Day. 2009. Efficacy of alternate day versus daily dosing of rosuvastatin. Canada Journal Cardiology 25:28-31. doi:10.1016/ S0828-282X(09)70480-5.

Ena, L., J. S. Lim, J. Y. Son, Y. J. Park, Y. H. Lee, J. Y. Kim, S. J. Kwack, B. M. Lee, M.-Y. Ahn, and H. S. Kim. 2018. Evaluation of subchronic exposure to triclosan on hepatorenal and reproductive toxicities in prepubertal rats. Journal of Toxicology and Environmental Health. Part A 81:421-31. doi:10.1080/15287394.2018.1451188.

Endres, M. 2006. Statins: Potential new indications in inflammatory conditions. Atherosclerosis Supplementary 7:31-35. doi:10.1016/j.atherosclerosissup.2006.01.005. 
Eskenazi, B., S. A. Kidd, A. R. Marks, E. Sloter, G. Block, and A. J. Wyrobek. 2005. Antioxidant intake is associated with semen quality in healthy men. Human Reprod 20:1006-12. doi:10.1093/humrep/deh725.

Favareto, A. P. A., F. C. de Toledo, and W. D. G. Kempinas. 2011. Paternal treatment with cisplatin impairs reproduction of adult male offspring in rats. Reproductive Toxicology (Elmsford, N.Y.) 32:425-33. doi:10.1016/j. reprotox.2011.10.003.

Fernandes, G. S. A., C. D. B. Fernandez, K. E. Campos, D. C. Damasceno, J. A. Anselmo-Franci, and W. D. G. Kempinas. 2011a. Vitamin C partially attenuates male reproductive deficits in hyperglycemic rats. Reproductive Biology and Endocrinology : RB\&E 100:1-9.

Fernandes, G. S. A., D. C. C. Gerardin, T. A. Assumpção, K. E. Campos, D. C. Damasceno, O. C. M. Pereira, and W. D. G. Kempinas. 2011b. Can vitamins $\mathrm{C}$ and $\mathrm{E}$ restore the androgen level and hypersensitivity of the vas deferens in hyperglycemic rats? Pharmacology Reports 63:983-91. doi:10.1016/S1734-1140(11)70614-4.

Guerra, M. T., M. Sanabria, S. V. Cagliarani, G. A. A. Leite, C. S. Borges, and W. G. Kempinas. 2017. Long-term effects of in utero and lactational exposure to butyl paraben in female rats. Environmental Toxicology 32:776-88. doi:10.1002/tox.22277.

Holdgate, G. A., W. H. J. Ward, and F. McTaggart. 2003. Molecular mechanism for inhibition of 3-hydroxy-3methylglutaryl CoA (HMG-CoA) reductase by rosuvastatin. Biochemical Society Transactions 31:528-31. doi:10.1042/bst0310528.

Hsieh, C. J., and B. Huang. 2016. Rosuvastatin decreases testosterone levels but not sexual function in men with type 2 diabetes. Diabetes Researcher Clinical Practical 120:81-88. doi:10.1016/j.diabres.2016.07.026.

Istvan, E. S. 2003. Statin inhibition of HMG-CoA reductase: A 3-dimensional view. Atherosclerosis Supplementary 4:38. doi:10.1016/S1567-5688(03)00003-5.

Istvan, E. S., and J. Deisenhofer. 2001. Structural mechanism for statin inhibition of HMG-CoA reductase. Science 292:1160-64. doi:10.1126/science.292.5522.1627b.

Izar, M. C. D. O., M. I. H. Fonseca, and F. A. H. Fonseca. 2011. Dyslipidemias. Reviews Bras Medica 68:59-73.

Jauniaux, E., L. Poston, and G. J. Burton. 2006. Placentalrelated diseases of pregnancy : Involvement of oxidative stress and implications in human evolution. Human Reprod. Update. 12:747-55. doi:10.1093/humupd/dml016.

Jiménez, E. G., and J. A. Ferre. 2011. Estatinas : Características $\mathrm{Y}$ efectos sobre El control lipídico en El Niño Y adolescente obeso. Reviews Clinical Medica Family 4:69-75.

Joyce, N. R., G. A. Wellenius, C. B. Eaton, A. N. Trivedi, and J. P. Zachariah. 2016. Patterns and predictors of medication adherence to lipid-lowering therapy in children aged 8 to 20 years. Journal Clinical Lipidology 10:824-32. doi:10.1016/j.jacl.2016.03.002.

Kwiterovich, P. O. 2008a. Clinical and laboratory assessment of cardiovascular risk in children: Guidelines for screening, evaluation, and treatment. Journal Clinical Lipidology 2:248-66. doi:10.1016/j.jacl.2008.06.003.

Kwiterovich, P. O. 2008b. Recognition and management of dyslipidemia in children and adolescents. The Journal of Clinical Endocrinology and Metabolism 93:4200-09. doi:10.1210/jc.2008-1270.

Leite, G. A. A., T. M. Figueiredo, M. T. Guerra, C. S. Borges, F. H. Fernandes, J. A. Anselmo-Franci, and W. D. G. Kempinas. 2018. Ascorbic acid co-administered with rosuvastatin reduces reproductive impairment in the male offspring from male rats exposed to the statin at pre-puberty. Food and Chemical Toxicology : an International Journal Published for the British Industrial Biological Research Association 118:416-29. doi:10.1016/j.fct.2018.05.043.

Leite, G. A. A., T. M. Figueiredo, T. L. Pacheco, M. Sanabria, P. V. Silva, F. H. Fernandes, and W. D. G. Kempinas. 2017b. Vitamin C partially prevents reproductive damage in adult male rats exposed to rosuvastatin during prepuberty. Food and Chemical Toxicology: an International Journal Published for the British Industrial Biological Research Association 109:272-83. doi:10.1016/j.fct.2017.09.003.

Leite, G. A. A., T. M. Figueiredo, M. Sanabria, A. F. M. G. Dias, P. V. Silva, A. C. Martins-Junior, F. Barbosa-Junior, and W. D. G. Kempinas. 2017a. Ascorbic acid supplementation partially prevents the delayed reproductive development in juvenile male rats exposed to rosuvastatin since prepuberty. Reproductive Toxicology (Elmsford, N.Y.) 73:328-38. doi:10.1016/j.reprotox.2017.07.006.

Leite, G. A. A., J. L. Rosa, M. Sanabria, M. M. Cavariani, J. A. Anselmo-Franci, P. F. F. Pinheiro, and W. D. G. Kempinas. 2014. Delayed reproductive development in pubertal male rats exposed to the hypolipemiant agent rosuvastatin since prepuberty. Reproductive Toxicology (Elmsford, N.Y.) 44:93103. doi:10.1016/j.reprotox.2014.01.004.

Liberman, J. N., J. E. Berger, and M. Lewis. 2009. Prevalence of antihypertensive, antidiabetic, and dyslipidemic prescription medication use among children and adolescents. Archives Pediatric Adolescent Medica 163:357-64. doi:10.1001/archpediatrics.2009.5.

Louis, G. W., D. R. Hallinger, L. J. Braxton, A. Kamel, and T. E. Stoker. 2017. Effects of chronic exposure to triclosan on reproductive and thyroid endpoints in the adult Wistar female rat. Journal of Toxicology and Environmental Health. Part A 80:236-48. doi:10.1080/15287394.2017.1287029.

Ludman, A., V. Venugopal, D. M. Yellon, and D. J. Hausenloy. 2009. Statins and cardioprotection - More than just lipid lowering? Pharmacology \& Therapeutics 122:30-43. doi:10.1016/j.pharmthera.2009.01.002.

Marcondes, F. K., F. J. Bianchi, and A. P. Tanno. 2002. Determination of the estrous cycle phases of rats: Some helpful considerations. Brazilian Journal Biologic 62:609-14.

Martin, P. D., P. D. Mitchell, and D. W. Schneck. 2002. Pharmacodynamic effects and pharmacokinetics of a new HMG-CoA reductase inhibitor, rosuvastatin, after morning or evening administration in healthy volunteers. British Journal Clinical Pharmacology 54:472-77. 
McTaggart, F. 2003. Comparative pharmacology of rosuvastatin. Atherosclerosis Supplementary 4:9-14. doi:10.1016/ S1567-5688(03)00004-7.

Mukhopadhyay, P. K., A. Dey, S. Mukherjee, and N. K. Pradhan. 2013. The effect of coadministration of alphatocopherol and ascorbic acid on arsenic trioxide-induced testicular toxicity in adult rats. Journal Basic Clinical Physiological Pharmacology 24:245-53. doi:10.1515/jbcpp2012-0039.

Olsson, A. G., F. McTaggart, and A. Raza. 2002. Rosuvastatin: A highly effective new HMG-CoA reductase inhibitor. Cardiovascular Drug Reviews 20:303-28. doi:10.1111/ j.1527-3466.2002.tb00099.x.

Ortega, I., A. B. Cress, D. H. Wong, J. A. Villanueva, A. Sokalska, B. C. Moeller, S. D. Stanley, and A. J. Duleba. 2012. Simvastatin reduces steroidogenesis by inhibiting Cyp17al gene expression in rat ovarian theca-interstitial cells. Biology of Reproduction 86:1-9. doi:10.1095/ biolreprod.111.094714.

Ortega, I., J. A. Villanueva, D. H. Wong, A. B. Cress, A. Sokalska, S. D. Stanley, and A. J. Duleba. 2014. Resveratrol potentiates effects of simvastatin on inhibition of rat ovarian theca-interstitial cells steroidogenesis. Journal Ovarian Researcher 21:1-8.

Pandir, D., O. Kara, and M. Kara. 2014. Protective effect of bilberry (Vaccinium myrtillus L.) on cisplatin induced ovarian damage in rat. Cytotechnology 66:677-85. doi:10.1007/s10616-013-9621-z.

Pattij, T., T. R. De Jong, A. Uitterdijk, M. D. Waldinger, J. G. Veening, A. R. Cools, P. H. van Der Graaf, and B. Olivier. 2005. Individual differences in male rat ejaculatory behaviour: Searching for models to study ejaculation disorders. The European Journal of Neuroscience 22:724-34. doi:10.1111/j.1460-9568.2005.04252.x.

Perobelli, J. E., T. R. Alves, F. C. De Toledo, C. D. B. Fernandez, J. A. Anselmo-Franci, G. R. Klinefelter, and W. D. G. Kempinas. 2012. Impairment on sperm quality and fertility of adult rats after antiandrogen exposure during prepuberty. Reproductive Toxicology (Elmsford, N.Y.) 33:308-15. doi:10.1016/j.reprotox.2011.04.005.

Perobelli, J. E., M. T. C. C. Patrão, C. D. B. Fernandez, M. Sanabria, G. R. Klinefelter, M. C. W. Avellar, and W. D. G. Kempinas. 2013. Androgen deprivation from pre-puberty to peripuberty interferes in proteins expression in pubertal and adult rat epididymis. Reproductive Toxicology (Elmsford, $\mathrm{N}$. Y.) 38:65-71. doi:10.1016/j.reprotox.2013.03.004.

Pfaff, D. W., and Y. Sakuma. 1979. Facilitation of the lordosis reflex of female rats from the ventromedial nucleus of the hypothalamus. Journal Physiological 288:189-202.

Picut, C. A., D. Dixon, M. L. Simons, D. G. Stump, G. A. Parker, and A. K. Remick. 2014a. Postnatal ovary development in the rat : Morphologic study and correlation of morphology to neuroendocrine parameters. Toxicogical Pathologists 43:343-53. doi:10.1177/0192623314544380.

Picut, C. A., A. K. Remick, M. G. Asakawa, M. L. Simons, and G. A. Parker. 2014b. Histologic features of prepubertal and pubertal reproductive development in female sprague- dawley rats. Toxicogical Pathologists 42:403-13. doi:10.1177/0192623313484832.

Reagan-Shaw, S., M. Nihal, and N. Ahmad. 2008. Dose translation from animal to human studies revisited. FASEB Journal : Official Publication of the Federation of American Societies for Experimental Biology 22:659-61. doi:10.1096/fj.07-9574LSF.

Ross, J. L. 2016. Statins in the management of pediatric dyslipidemia. Journal Pediatric Nursing 31:723-35. doi:10.1016/j.pedn.2016.07.004.

Schagdarsurengin, U., and K. Steger. 2016. Epigenetics in male reproduction: Effect of paternal diet on sperm quality and offspring health. Natural Reviews Urolology 13:584-95. doi:10.1038/nrurol.2016.157.

Shaikh, A. A. 1971. Estrone and estradiol levels in the ovarian venous blood from rats during the estrous cycle and pregnancy. Biology of Reproduction 5:297-307. doi:10.1093/biolre$\operatorname{prod} / 5.3 .297$.

Shrilatha, B., and Muralidhara. 2007. Early oxidative stress in testis and epididymal sperm in streptozotocin-induced diabetic mice: Its progression and genotoxic consequences. Reproductive Toxicology (Elmsford, N.Y.) 23:578-87. doi:10.1016/j.reprotox.2007.02.001.

Silva, P. V., R. F. Silva, C. S. Borges, M. M. Cavariani, C. C. D. Almeida-Francia, F. Barbosa-Junior, and W. D. G. Kempinas. 2016. Sexual differentiation and reproductive development of female rat offspring after paternal exposure to the anti-tumor pharmaceutical cisplatin. Reproductive Toxicology (Elmsford, N.Y.) 60:112-22. doi:10.1016/j.reprotox.2016.02.005.

Sönmez, M., G. Turk, and A. Yuce. 2005. The effect of ascorbic acid supplementation on sperm quality, lipid peroxidation and testosterone levels of male wistar rats. Theriogenology 63:2063-72. doi:10.1016/j.theriogenology.2004.10.002.

Sooriyaarachchi, M., A. Narendran, and J. Gailer. 2012. The effect of sodium thiosulfate on the metabolism of cisplatin in human plasma in vitro. Metallomics : Integrated Biometal Science 4:960-67. doi:10.1039/c2mt20076g.

Stoker, T. E., S. C. Laws, D. L. Guidici, and R. L. Cooper. 2000. The effect of atrazine on puberty in male Wistar rats: An evaluation in the protocol for the assessment of pubertal development and thyroid function. Toxicological Sciences : an Official Journal of the Society of Toxicology 58:50-59. doi:10.1093/toxsci/58.1.50.

Talsness, C. E., M. Shakibaei, S. N. Kuriyama, S. W. Grande, A. Sterner-Kock, P. Schnitker, C. Souza, K. Grote, and I. Chahoud. 2005. Ultrastructural changes observed in rat ovaries following in utero and lactational exposure to low doses of a polybrominated flame retardant. Toxicology Letters 157:189-202. doi:10.1016/j.toxlet.2005.02.001.

Tandon, V., G. Bano, V. Khajuria, A. Parihar, and S. Gupta. 2005. Pleiotropic effects of statins. Indian Journal Pharmacology 37:77-85. doi:10.4103/0253-7613.15106.

U.S. Environmental Protection Agency. 1996. Guidelines for reproductive toxicity risk assessment. E. P. A. 61: 56274-322.

Uslu, U., S. Sandal, A. Cumbul, S. Yildiz, M. Aydin, and B. Yilmaz. 2013. Evaluation of estrogenic effects of polychlorinated biphenyls and organochlorinated pesticides 
using immature rat uterotrophic assay. Human Exp. Toxicology 32:476-82. doi:10.1177/0960327112472999.

Vaughan, C. J., and A. M. Gotto, Jr. 2004. Update on statins: 2003. Circulation 110:886-92. doi:10.1161/01. CIR.0000139312.10076.BA.

Veening, J. G., L. M. Coolen, and P. O. Gerrits. 2013. Neural mechanisms of female sexual behavior in the rat: Comparison with male ejaculatory control. Pharmacology, Biochemistry, and Behavior 121:16-30. doi:10.1016/j.pbb.2013.11.025.

Weathherly, L. M., and J. A. Gosse. 2017. Triclosan exposure, transformation and human health effects. Journal Toxicogical Environment Health B 20:447-69. doi:10.1080/ 10937404.2017.1399306.

Westwood, F. R. 2008. Toxicologic pathology the female rat reproductive cycle : A practical histological guide to staging. Toxicogical Pathologists 36:375-84. doi:10.1177/ 0192623308315665.

Wiegman, A., S. S. Gidding, G. F. Watts, M. J. Chapman, H. N. Ginsberg, M. Cuchel, and L. Ose. 2015. Familial hypercholesterolaemia in children and adolescents: Gaining decades of life by optimizing detection and treatment. European Heart Journal 36:2425-37. doi:10.1093/eurheartj/ehv157.

Young, J. I., S. Zuchner, and G. Wang. 2015. Regulation of epigenome by vitamin C. Annual Review of Nutrition 35:545-64. doi:10.1146/annurev-nutr-071714-034228.

Zhao, X., Z. Cheng, Y. Zhu, S. Li, L. Zhang, and Y. Luo. 2015. Effects of paternal cadmium exposure on the sperm quality of male rats and the neurobehavioral system of their offspring. Experiments Therapeutics Medica 10:2356-60. doi:10.3892/etm.2015.2777. 